\title{
Diversity and dynamics of Archaea in an activated sludge wastewater treatment plant
}

\author{
Nils Johan Fredriksson ${ }^{1 *}$, Malte Hermansson ${ }^{2}$ and Britt-Marie Wilén ${ }^{1}$
}

\begin{abstract}
Background: The activated sludge process is one of the most widely used methods for treatment of wastewater and the microbial community composition in the sludge is important for the process operation. While the bacterial communities have been characterized in various activated sludge systems little is known about archaeal communities in activated sludge. The diversity and dynamics of the Archaea community in a full-scale activated sludge wastewater treatment plant were investigated by fluorescence in situ hybridization, terminal restriction fragment length polymorphism analysis and cloning and sequencing of 165 rRNA genes.

Results: The Archaea community was dominated by Methanosaeta-like species. During a 15 month period major changes in the community composition were only observed twice despite seasonal variations in environmental and operating conditions. Water temperature appeared to be the process parameter that affected the community composition the most. Several terminal restriction fragments also showed strong correlations with sludge properties and effluent water properties. The Archaea were estimated to make up $1.6 \%$ of total cell numbers in the activated sludge and were present both as single cells and colonies of varying sizes.

Conclusions: The results presented here show that Archaea can constitute a constant and integral part of the activated sludge and that it can therefore be useful to include Archaea in future studies of microbial communities in activated sludge.
\end{abstract}

\section{Background}

The activated sludge process is one of the most widely used methods for treatment of wastewater. An important factor for the operation of activated sludge wastewater treatment plants (WWTPs) is the solid-liquid separation in which flocculation and settling are important processes [1]. Poor flocculation and settling of the activated sludge lead to poor effluent quality and can cause environmental problems in the receiving waters. The sludge characteristics depend on the microbial community composition [2-4], the microbial activity [5] and the properties of the extra-cellular polymeric substances in the flocs [6,7]. The bacterial community has been characterized in a number of activated sludge systems $[8,9]$ but very little is known about archaeal communities in sludge. The presence of Archaea in activated sludge has been shown by fluorescence in situ hybridization

\footnotetext{
* Correspondence: johan.fredriksson@chalmers.se

${ }^{1}$ Department of Civil and Environmental Engineering, Water Environment

Technology, Chalmers University of Technology, Gothenburg, Sweden
}

Full list of author information is available at the end of the article
(FISH), e.g. [10]. Methanogens [11,12] and putative ammonia-oxidizing Archaea (AOA) [13-15] have been detected by amplification of $16 \mathrm{~S}$ rRNA and archaeal ammonia monooxygenase subunit A genes. Although present, Archaea seem to be of minor importance for both nitrogen and carbon removal $[11,16]$. However, it is still possible that the Archaea have other functions or affect the properties of the activated sludge. Addition of methanogens to the sludge in intermittently aerated bioreactors increased the rates of specific oxygen uptake, denitrification and nitrification suggesting a symbiotic relationship with Bacteria [17]. The composition of the methanogenic community in anaerobic sludge has been shown to be crucial for the structure and integrity of granules [18-20] and if methanogens are present in activated sludge they may contribute to the floc structure.

This study had three aims. The first was to describe the Archaea community in the activated sludge of a fullscale WWTP by cloning and sequencing of 16S rRNA genes. Although there are many studies where activated sludge samples have been screened for the presence of

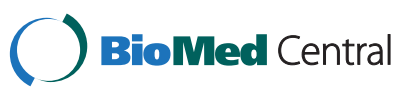


AOA (e.g. [13-15]), to our knowledge there are only two published studies on the diversity of Archaea in activated sludge from a full-scale WWTP [11,12]. One of the studies investigated two small WWTPs [11] and the other a seawater-processing WWTP [12]. The Rya WWTP is a large WWTP treating municipal and industrial wastewater, thus different from the WWTPs in those two studies. Since little is known about Archaea in WWTPs and, importantly, sequence coverage for Archaea from WWTPs is still modest, the 16S rRNA sequences we obtained here would indicate if published FISH probes were relevant. If so, the second aim was to quantify the Archaea by confocal microscopy and FISH and to determine their localization in the flocs. The third aim was to follow the dynamics of the Archaea community for a longer period of time using terminal restriction fragment length polymorphism (T-RFLP) analysis. For the third aim, the samples that were used were collected for previous studies of the dynamics of the floc composition and flocculation and settling properties of the activated sludge at the Rya WWTP [21,22]. Analyzing the Archaea community in the same samples could give an indication of possible causes or effects of Archaea community changes.

\section{Results}

\section{Observed and estimated richness of the Archaea}

\section{community in the activated sludge}

A $16 \mathrm{~S}$ rRNA gene clone library was constructed from a sample of activated sludge collected at the aeration tank of the Rya WWTP at a time of normal operating conditions. There were no atypical process parameter values or extreme events prior to sample collection. However, the F/M-ratio was higher at the time of the clone library sample collection (May 2007) compared with the times when samples were collected for FISH (December 2007) and T-RFLP analyses (May 2003 - August 2004) (Table 1). Cloning and sequencing generated 82 archaeal
16S rRNA gene sequences of lengths between 756 and 862 bases. Based on DNA similarity the sequences were assigned to operational taxonomic units (OTUs). The sequences were assigned to OTUs corresponding to 25 species of 10 genera, 7 families/classes and 6 different phyla. The Archaea community richness was estimated to be at least 43 species of 19 different genera. Thus, the clone library covered at most $58 \%$ of the species and $53 \%$ of the genera present in the activated sludge. Accumulation curves (Figure 1) also illustrate that the clone library does not fully cover the Archaea community.

\section{Evenness and functional organization}

Figure 2 shows a Pareto-Lorenz evenness curve of the Archaea community based on the relative abundances of the 25 OTUs obtained by applying a $98.7 \%$ sequence similarity threshold. The functional organization (Fo) index, the combined relative abundance of $20 \%$ of the OTUs, is $56 \%$, meaning that more than half of the observed sequences belong to only five of the observed OTUs. A high Fo index is an indication of a specialized community since it means that a big part of the population belongs to a small number of OTUs and performs a small number of ecological functions. In a completely even community all OTUs would have the same number of individuals and it would be possible for a large number of different functions to be equally abundant. In the clone library, the five most abundant OTUs, which include $56 \%$ of the sequences, all belong to Methanosaeta and presumably are all methanogens. Furthermore, the composition of the clone library indicates that the community includes a small number of ecological functions since 13 of 25 OTUs, including $77 \%$ of the sequences, were identified as Methanosaeta (Figure 3).

Comparison with available sequences in GenBank and SILVA Searches in GenBank using BLAST [25] and in the SILVA rRNA database [26] found sequences with a sequence

Table 1 Comparison of WWTP parameters at the different sample collection times ${ }^{\text {a }}$

\begin{tabular}{|c|c|c|c|c|}
\hline Parameter ${ }^{b, c, d}$ & May $03-$ Aug $04{ }^{\mathrm{e}}$ & May $07^{f}$ & $\operatorname{Dec} 07^{\mathrm{g}}$ & Comment \\
\hline Temp $^{b}$ & $15 \pm 3$ & $15 \pm 1$ & $11 \pm 1 * *$ & \\
\hline $\mathrm{SRT}^{\mathrm{b}}$ & $3 \pm 1$ & $3 \pm 0$ & $2 \pm 0$ & \\
\hline$F / M^{b}$ & $0.008 \pm 0.002$ & $0.014 \pm 0.004 * *$ & $0.008 \pm 0.002$ & Max value in May 2007 \\
\hline $\operatorname{COD}^{b}$ & $1058 \pm 240$ & $999 \pm 194$ & $1068 \pm 97 \pm$ & \\
\hline NO23-N ${ }^{b}$ & $48 \pm 8$ & $46 \pm 9$ & $42 \pm 22$ & Min and max values in Dec 07 \\
\hline SSVI ${ }^{c}$ & $80 \pm 15$ & 54 & 79 & \\
\hline Effluent NSS ${ }^{c}$ & $23 \pm 17$ & 26 & 31 & \\
\hline
\end{tabular}




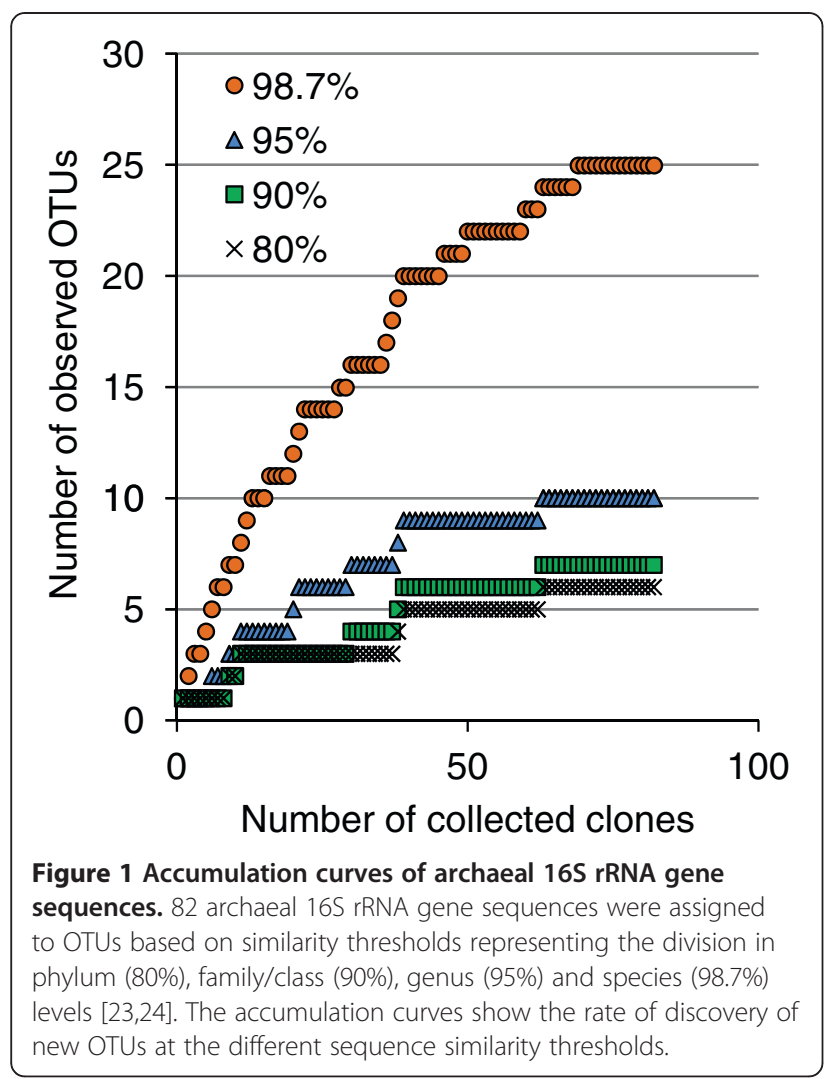

similarity of $98.7 \%$ or higher for 22 of 25 OTUs, including 78 of the 82 sequences (Table 2). With $100 \%$ coverage, 4 sequences could only be matched with sequence similarities lower than $98.7 \%$ and may therefore represent new species belonging to the genera Methanosaeta (OTU10 and OTU16) or the Thermoplasmatales, Cluster $B$ (OTU20). The most similar sequences in the databases were from various types of soil environments, water environments and anaerobic bioreactors in North America, Europe and Asia. For 30 of the 82 sequences, the best match came from an anaerobic bioreactor.

\section{Phylogenetic tree analysis}

The phylogenetic affiliation of the obtained $16 \mathrm{~S}$ rRNA gene sequences was determined by phylogenetic tree analysis. A phylogenetic tree for Euryarchaea inferred by maximum likelihood analysis is shown in Figure 4. A phylogenetic tree for Crenarchaea and Thaumarchaea inferred by maximum likelihood analysis is shown in Figure 5. The majority of the sequences were determined to be of genus Methanosaeta (Figure 3). Several sequences also affiliated with divisions of uncultured Archaea.

\section{Dynamics of the Archaea community}

The community composition, as assessed by T-RFLP, changed little throughout the monitored period. The difference, measured as Bray-Curtis distance, between the

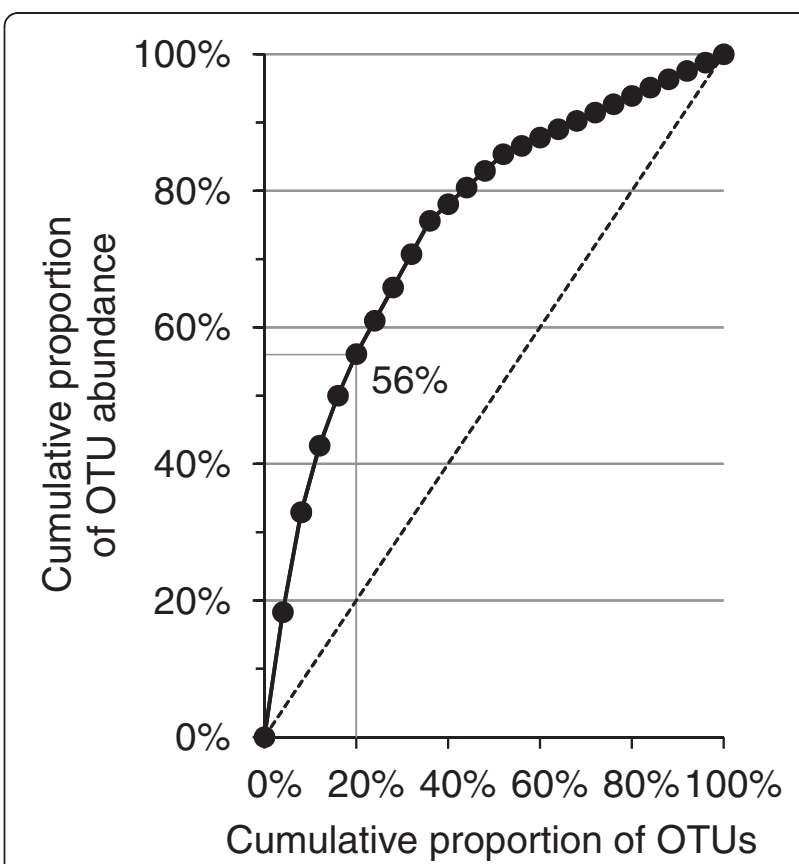

Figure 2 Pareto-Lorenz evenness curve. 82 archaeal 16S rRNA gene sequences were divided in 25 OTUs based on a sequence similarity threshold of $98.7 \%$ and the OTUs were ranked from high to low, based on their abundance. The Pareto-Lorenz evenness curve is the plot of the cumulative proportion of OTU abundances (y-axis) against the cumulative proportion of OTUs (x-axis). The Fo index, i.e. the combined relative abundance of $20 \%$ of the OTUs, is shown. The dotted straight line is the Pareto-Lorenz curve of a community with perfect evenness.

terminal restriction fragment (TRF) profile of the first sample in the time series, May 16, 2003, and all following samples was on average only $5.8 \pm 6.3 \%$ and $5.4 \pm 7.1 \%$ for the AluI and RsaI analysis, respectively (Figure 6). On two occasions, in October 2003 and in January 2004, the Bray-Curtis distance peaked, indicating a deviation from the community composition at the beginning of the time series. The difference between the TRF profiles of May 16, 2003 and May 22, 2007, four years later, was $10 \%$ and $0 \%$ for the AluI and RsaI analysis, respectively. However, the sensitivity of the T-RFLP analysis is limited and TRFs of low abundance cannot be detected. Thus, a Bray-Curtis distance of $0 \%$ between the TRF profiles of two samples does not indicate identical community composition since there may be differences in the composition of Archaea of low abundance. To get a rough estimate of the sensitivity of the T-RFLP method, a comparison was made between the theoretical TRF profile of the clone library and the observed TRF profile from the same sample. The comparison showed that only TRFs with a relative abundance higher than $20 \%$ in the clone library were observed in the TRF profile (Table 3 ). Thus, the T-RFLP analysis shows the dynamics of the major groups of Archaea in the 


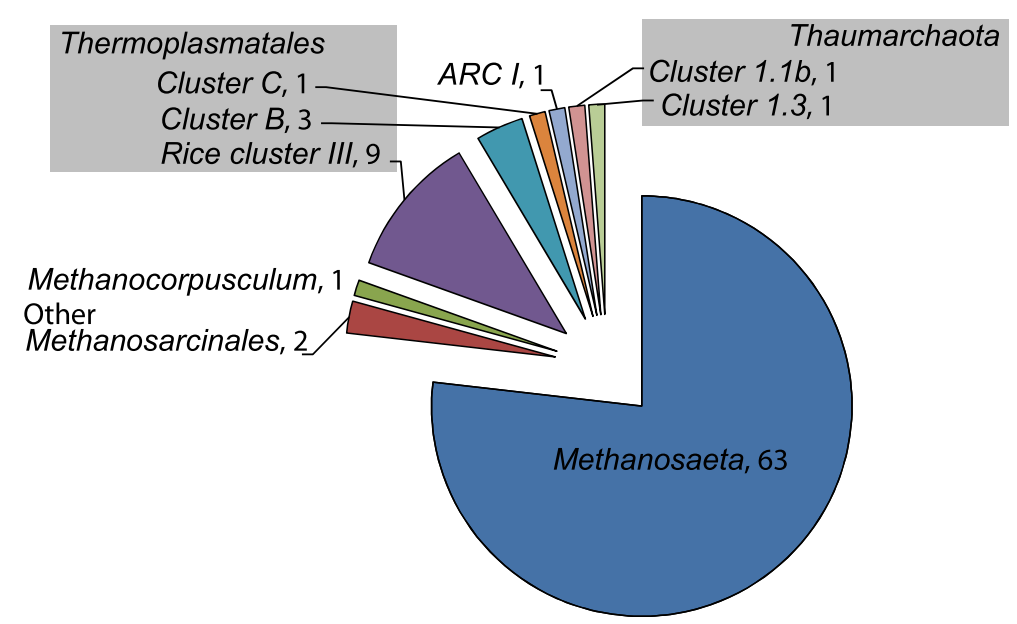

Figure 3 Community composition. The 82 16S rRNA gene sequences were classified according to the phylogenetic tree analysis. The number of sequences within each group is given.

activated sludge. The relative abundances of the observed TRFs in all TRF profiles in the time series are shown in Figures 7 and 8.

To identify the TRFs the observed TRF lengths were compared with the predicted TRF lengths of sequences in the clone library. The predicted TRFs from the sequences in the clone library were between 4 and 6 bases longer than the observed TRFs (Table 3). Such a discrepancy between observed and predicted TRF sizes is commonly observed [32,33]. Not all observed TRFs in the time series could be matched with the predicted TRFs of the clone library sequences. To explore the possibility that the TRFs in the TRF profiles from the samples from 2003 and 2004 come from sequences other than those found in the clone library a comparison was also made with a database of 5802 archaeal 16S rRNA gene sequences matching the primers used in this study. The database was checked for sequences that would result in any of the observed combinations of TRFs generated by AluI and RsaI. The result of the analysis was a number of possible identities for each observed combination of AluI and RsaI TRFs (Table 4). Although the database comparison may result in false identities of the TRFs, it is valuable because it gives an indication about the range of species that could give the observed TRF combinations. By comparison with the clone library sequences the dominating TRFs (AluI 176, AluI 184, RsaI 74 and RsaI 238) were determined to represent Methanosaeta-like species. Comparisons with the predicted TRFs of 5802 Archaea sequences in the database (Table 4) showed that it is possible that the dominating TRFs are from other species of the Euryarchaeota than Methanosaeta. However, it is unlikely that the origin of these TRFs is species of the Crenarchaeota or Thaumarchaeota, since all the Crenarchaeota or Thaumarchaeota sequences in the databases have other predicted TRF lengths.

\section{Correlation analysis}

Several TRFs showed a significant correlation with process parameters (Table 5). The parameters that correlated with most TRFs were water temperature and nitrogen concentration. There were also significant correlations between several TRFs and the sludge and effluent water properties (Table 6). The parameter effluent non-settleable solids (NSS) and the concentration of carbohydrates in extracted extracellular polymeric substances (EPS) correlated with most TRFs. No TRF showed a significant correlation with the sludge volume or shear sensitivity.

\section{Quantification and localization of Archaea in the activated sludge flocs}

The 16S rRNA gene clone library indicated that published FISH probes would cover the Archaea at Rya WWTP. Archaea could be observed in the activated sludge flocs, both centrally located and close to the edges of the flocs. FISH analyses showed that the average relative abundance of Archaea in the activated sludge of the aeration tank was $1.6 \%$ (Figure 9). In the anaerobic digester and in the water recycled into the activated sludge tanks (reject water) there were more Archaea than Bacteria (Figure 9). In most images of activated sludge flocs the percentage of Archaea was lower than 2\% (Figure 10). Occasionally there were larger colonies of Archaea (Figure 11, panel A) but in most images Archaea were either present as individual cells or small colonies (Figure 11, panel B). 
Table 2 Database comparisons

\begin{tabular}{|c|c|c|c|c|c|}
\hline \multirow[b]{2}{*}{ OTU } & \multicolumn{5}{|l|}{ Database match ${ }^{a}$} \\
\hline & $\overline{\text { Matching clones }}$ & Acc. no. & Identity $^{b}$ & Taxonomy & Source environment \\
\hline \multirow[t]{4}{*}{$\overline{\text { OTU1 }}$} & 1 & CU917405 & 99.8 & Methanosaeta & Digester \\
\hline & 6 & CU917423 & $99.6-100$ & Methanosaeta & Digester \\
\hline & 6 & CU917466 & $99.8-100$ & Methanosaeta & Digester \\
\hline & 2 & $J F 280185$ & 100.0 & Methanosaeta & High mountain hot spring \\
\hline \multirow[t]{5}{*}{ OTU2 } & 2 & AJ831102 & 99.9 & Archaea & Landfill drainage layer \\
\hline & 4 & СР002565 & 100.0 & Methanosaeta concilii & Strain GP6 \\
\hline & 1 & CU916678 & 100.0 & Methanosaeta & Digester \\
\hline & 3 & CU917245 & $99.9-100$ & Methanosaeta & Digester \\
\hline & 2 & FR832406 & $99.9-100$ & Methanosaeta concilii & Digester \\
\hline \multirow[t]{3}{*}{ OTU3 } & 6 & СР002565 & $99.9-100$ & Methanosaeta concilii & Strain GP6 \\
\hline & 1 & CU915936 & 100.0 & Methanosaeta & Digester \\
\hline & 1 & CU916215 & 99.9 & Methanosaeta & Digester \\
\hline \multirow[t]{2}{*}{ OTU4 } & 3 & AF050611 & $99.6-99.9$ & Methanosaeta & Contaminated aquifer \\
\hline & 3 & EU155906 & 99.3 & Archaea & Rich minerotrophic fen \\
\hline \multirow[t]{2}{*}{ OTU5 } & 2 & AJ831108 & 99.9 & Archaea & Landfill drainage layer \\
\hline & 3 & CP002565 & $99.6-100$ & Methanosaeta concilii & Strain GP6 \\
\hline OTU6 & 4 & EU155906 & $99.0-99.2$ & Archaea & Rich minerotrophic fen \\
\hline OTU7 & 4 & GU591511 & $98.8-99.1$ & Archaea & Microbial fuel cell \\
\hline OTU8 & 4 & GU591511 & $98.6-99.1$ & Archaea & Microbial fuel cell \\
\hline \multirow[t]{2}{*}{ OTU9 } & 3 & EU155906 & $98.7-99.2$ & Archaea & Rich minerotrophic fen \\
\hline & 1 & AY667272 & 98.7 & Archaea & TCE-dechlorinating groundwater \\
\hline \multirow[t]{2}{*}{ OTU10 } & 1 & EU155954 & 93.5 & Archaea & Rich minerotrophic fen \\
\hline & 1 & FN691755 & 93.0 & Archaea & Lake Llebreta \\
\hline \multirow[t]{2}{*}{ OTU11 } & 1 & CU917466 & 99.9 & Methanosaeta & Digester \\
\hline & 1 & CU916809 & 99.8 & Methanosaeta & Digester \\
\hline OTU12 & 2 & AJ576227 & $99.5-99.9$ & Archaea & Landfill leachate \\
\hline \multirow[t]{2}{*}{ OTU13 } & 1 & HM244086 & 99.0 & Archaea & Lake sediment \\
\hline & 1 & AF050611 & 100.0 & Methanosaeta & Contaminated aquifer \\
\hline OTU14 & 1 & HQ592619 & 99.5 & Archaea & Activated sludge \\
\hline OTU15 & 1 & FR749947 & 98.9 & Methanocorpusculum sinense & Strain DSM $4274 \mathrm{~T}$ \\
\hline OTU16 & 1 & AY693812 & 97.6 & Euryarchaea & Anaerobic sludge \\
\hline OTU17 & 1 & FR832415 & 99.8 & Methanosaeta concilii & Digester \\
\hline OTU18 & 1 & CU917031 & 100.0 & Archaea & Digester \\
\hline OTU19 & 1 & AJ576235 & 99.8 & Archaea & Landfill leachate \\
\hline OTU20 & 1 & AF050619 & 98.4 & Euryarchaeota & Contaminated aquifer \\
\hline OTU21 & 1 & AB353220 & 99.2 & Euryarchaeota & Thermophilic digested sludge \\
\hline OTU22 & 1 & HQ316970 & 100.0 & Crenarchaeota & Wastewater treatment plant, oil refinery \\
\hline OTU23 & 1 & FR832415 & 98.8 & Methanosaeta concilii & Digester \\
\hline OTU24 & 1 & EU399655 & 99.2 & Archaea & Phenol-degrading sludge \\
\hline OTU25 & 1 & CU917014 & 99.9 & Archaea & Digester \\
\hline
\end{tabular}

a Best matching entry in GenBank or the SILVA rRNA database with $100 \%$ coverage. ${ }^{\mathrm{b}}$ Identity in $\%$. 


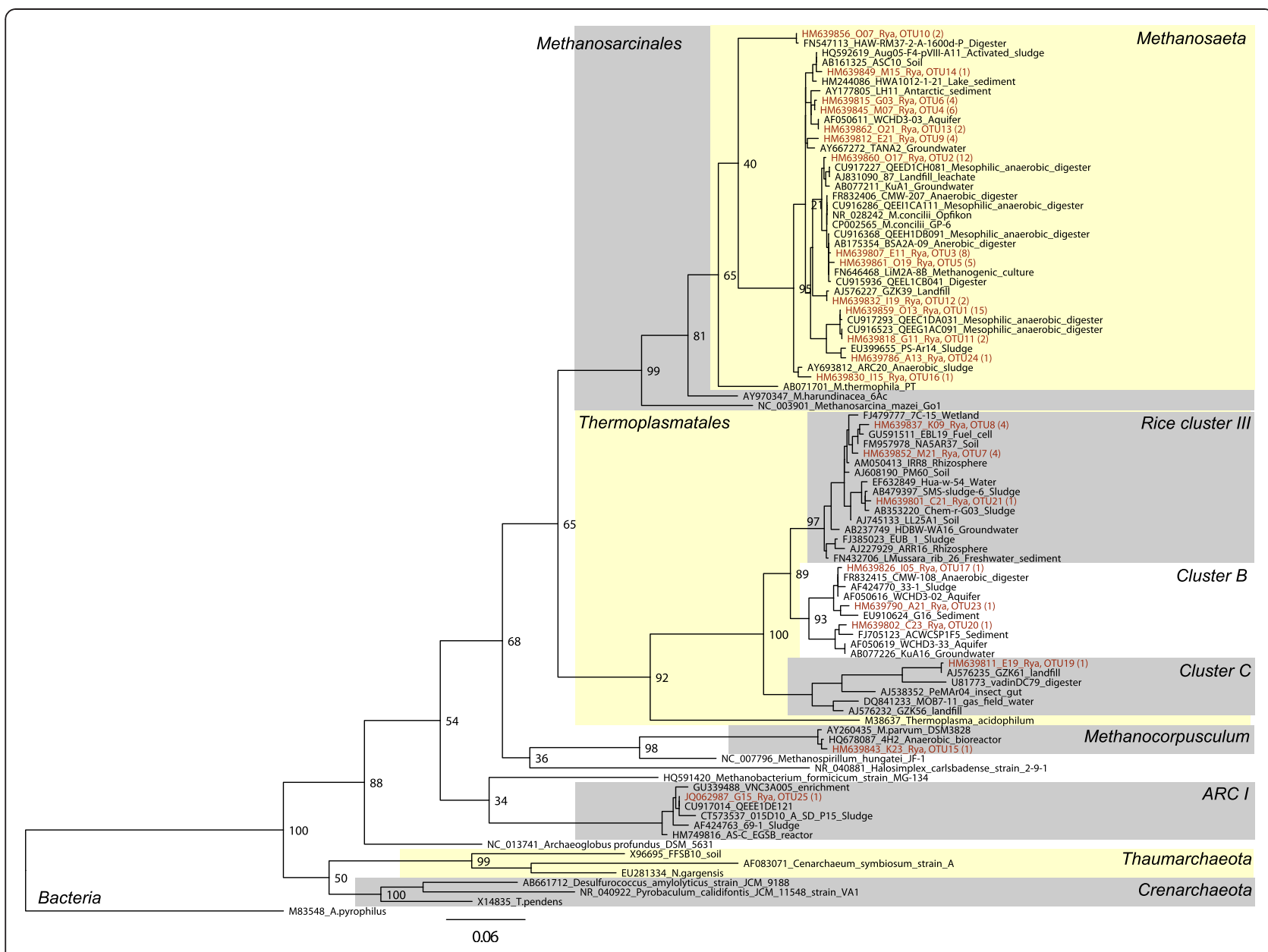

Figure 4 Phylogenetic tree of archaeal 16S rRNA genes. Consensus tree constructed from 100 maximum likelihood trees. The branch lengths and the scale bar are proportional to nucleotide differences. Bootstrap values out of a total of 100 are given at the nodes. The sequence of Aquifex pyrophilus was used as outgroup. The OTU numbers of the Rya WWTP sequences are given with the total number of sequences within that OTU in parentheses. The cluster names are in accordance with Kemnitz [27], Grosskopf [28] and Chouari [29].

\section{Discussion}

In this study the abundance, localization, composition and dynamics of Archaea in the activated sludge of a full-scale WWTP were assessed using FISH analysis, 16S rRNA gene clone library analysis and T-RFLP time series analysis. These three analyses were all done on samples collected at different times. However, for most process parameters there were no significant differences between these times (Table 1). The WWTP was also operated the same way at all times, except for four months, May 24 to September 24, 2004, when the primary settlers were bypassed. The samples were therefore considered comparable.

The T-RFLP time series analysis showed that the most abundant TRFs were the same throughout 2003 and 2004 as well as in May 2007 (Figures 7 and 8). If we assume that the same TRF always represent the same group of Archaea, then the T-RFLP data show that the main part of the Archaea community was the same in 2003, 2004 and in May 2007 (Figures 7 and 8) and that we can use the clone library data to identify the TRFs in the T-RFLP time series. We further assume that the Archaea community stayed mainly the same in December 2007, which make it possible to use the clone library data to choose appropriate probes for the FISH analysis.

The clone library sequences indicated that already published FISH probes were relevant for an estimation of the relative abundance of major Archaea groups. The relative abundance of the Archaea has been estimated in other investigations to be low, based on activity measurements [11], and up to $8 \%$ of Bacteria [10] or $10 \%$ of total cell numbers [16]. In this study Archaea was estimated, by FISH, to make up $1.6 \%$ of total cell numbers in the activated sludge, a relatively low abundance. 


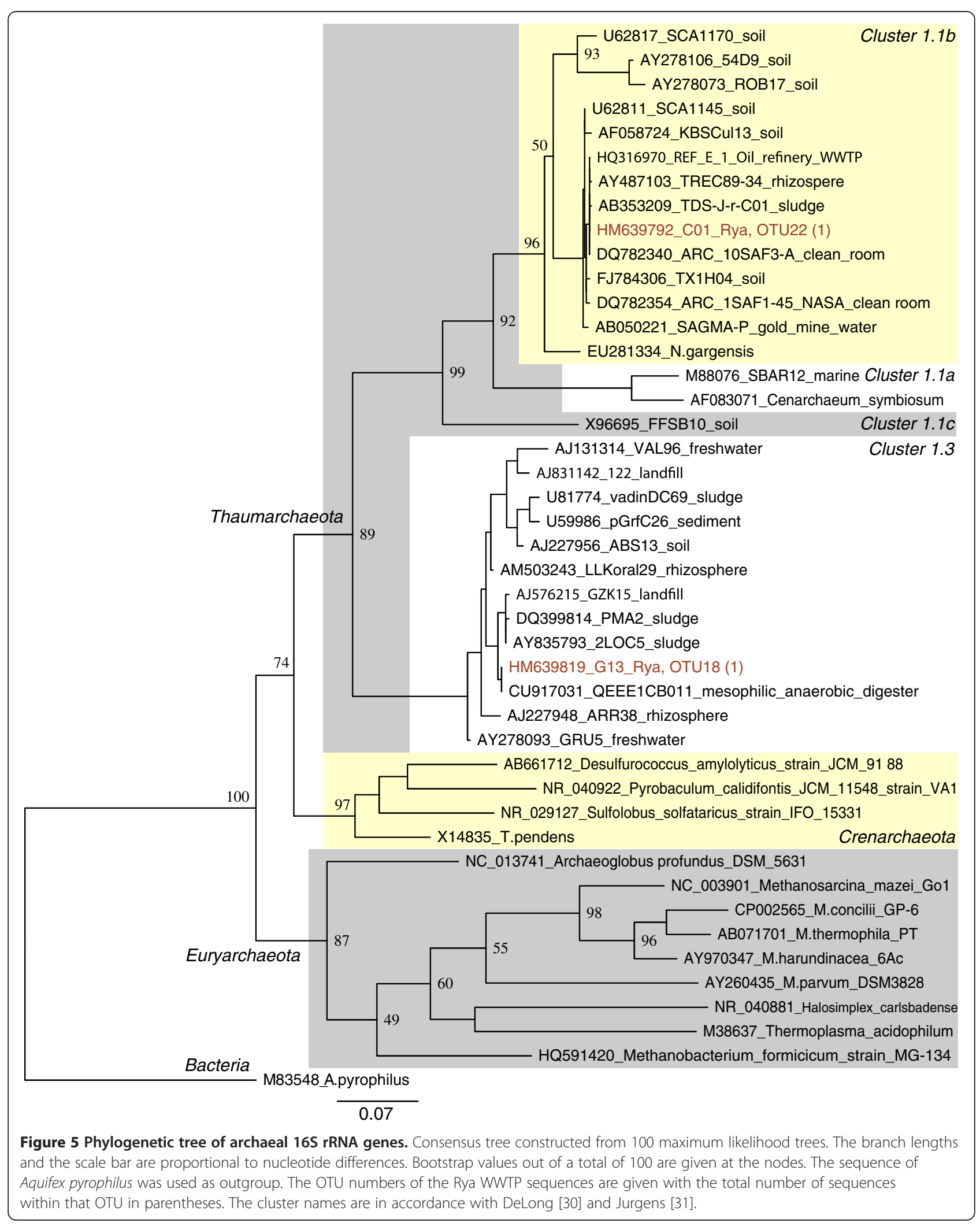




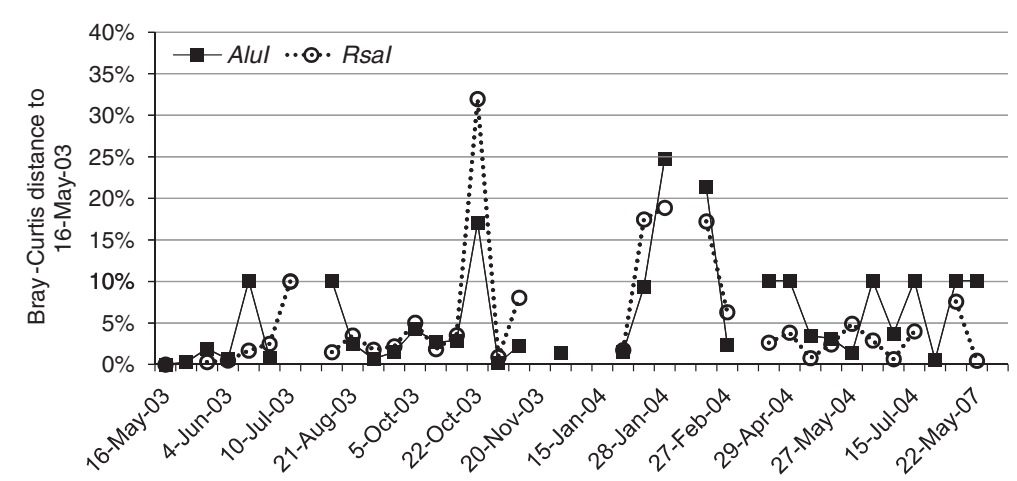

Figure 6 Community stability. The stability of the archaeal community is illustrated by plotting the difference, measured as Bray-Curtis distance, between the TRF profile of the first sample in the time series, May 16, 2003, and all following samples. The Bray-Curtis distance is calculated by comparing the relative abundances of the TRFs in the TRF profiles and is low for similar profiles. Results from both the Alul and the Rsal analysis are shown.

However, the importance of a microbial group cannot be deduced by abundance alone. Putative AOA were 1-10\% of total cell numbers in activated sludge, but despite this abundance they did not contribute significantly to nitrification [16], whereas foaming organisms have great impact on floc structure and sludge properties even when present in numbers around 1\% [35,36]. Another example is ammonium oxidizers, which at an abundance of $3-5 \%$ (of total bacteria), could perform the first step in a successful $80 \%$ reduction of nitrogen in an activated sludge system [37]. Thus, despite their relatively low abundance, a possible contribution of Archaea to sludge properties cannot be ruled out.
The composition of the Archaea community was investigated by analysis of $8216 \mathrm{~S}$ rRNA sequences. The community richness was estimated to be 43 species of 19 genera. As expected, the clone library does not fully cover the Archaea community (Figure 1). However, the 25 species of 10 genera that were observed are assumed to represent the most abundant groups. The Archaea community was functionally specialized (Figure 2) with $77 \%$ of the sequences in the clone library being Methanosaeta-like organisms (Figure 3). Specialized communities dominated by methanogens, although of other genera than Methanosaeta, have also been observed in activated sludge from other WWTPs $[11,12]$.

Table 3 Observed and predicted TRF lengths ${ }^{\text {a }}$

\begin{tabular}{|c|c|c|c|c|c|c|c|}
\hline \multicolumn{4}{|c|}{ Observed TRF lengths T-RFLP 2007-05-22 } & \multicolumn{4}{|c|}{ Predicted TRF lengths, clone library 2007-05-22 } \\
\hline Alul & $\%^{\mathbf{b}}$ & Rsal & $\%^{\mathbf{b}}$ & Alul & Rsal & $\%^{c}$ & Identity \\
\hline & & & & 84 & 80 & $1 \%$ & Thaumarchaeota/Cluster 1.3 \\
\hline & & & & 126 & 608 & $1 \%$ & Thermoplasmatales/Cluster B \\
\hline & & & & 166 & 609 & $2 \%$ & Thermoplasmatales/Cluster B \\
\hline & & & & 180 & 80 & $4 \%$ & Methanosaeta \\
\hline \multirow[t]{11}{*}{183} & $100 \%$ & 74 & $86 \%$ & 188 & 80 & $48 \%$ & Methanosaeta \\
\hline & & 238 & $14 \%$ & 188 & 242 & $21 \%$ & Methanosaeta \\
\hline & & & & 188 & $N D^{d}$ & $2 \%$ & Methanosaeta \\
\hline & & & & 189 & 264 & $1 \%$ & $A R C I$ \\
\hline & & & & 359 & 262 & $1 \%$ & Thaumarchaeota/Cluster 1.16 \\
\hline & & & & 400 & 609 & $1 \%$ & Thermoplasmatales/RCIII \\
\hline & & & & 515 & 264 & $1 \%$ & Methanocorpusculum \\
\hline & & & & 551 & 609 & $10 \%$ & Thermoplasmatales/RCIII \\
\hline & & & & ND & 80 & $1 \%$ & Methanosaeta \\
\hline & & & & ND & 613 & $1 \%$ & Thermoplasmatales/Cluster C \\
\hline & & & & ND & ND & $4 \%$ & Methanosaeta \\
\hline
\end{tabular}

a Observed and predicted TRF lengths from T-RFLP and clone library analysis of a sample from 2007-05-22. ${ }^{\mathrm{b}}$ Relative abundance based on total fluorescence. ${ }^{c}$ Relative abundance based on frequency in clone library. ${ }^{d}$ ND indicates cases where a TRF could not be predicted or where the predicted TRF was outside the detection range. 


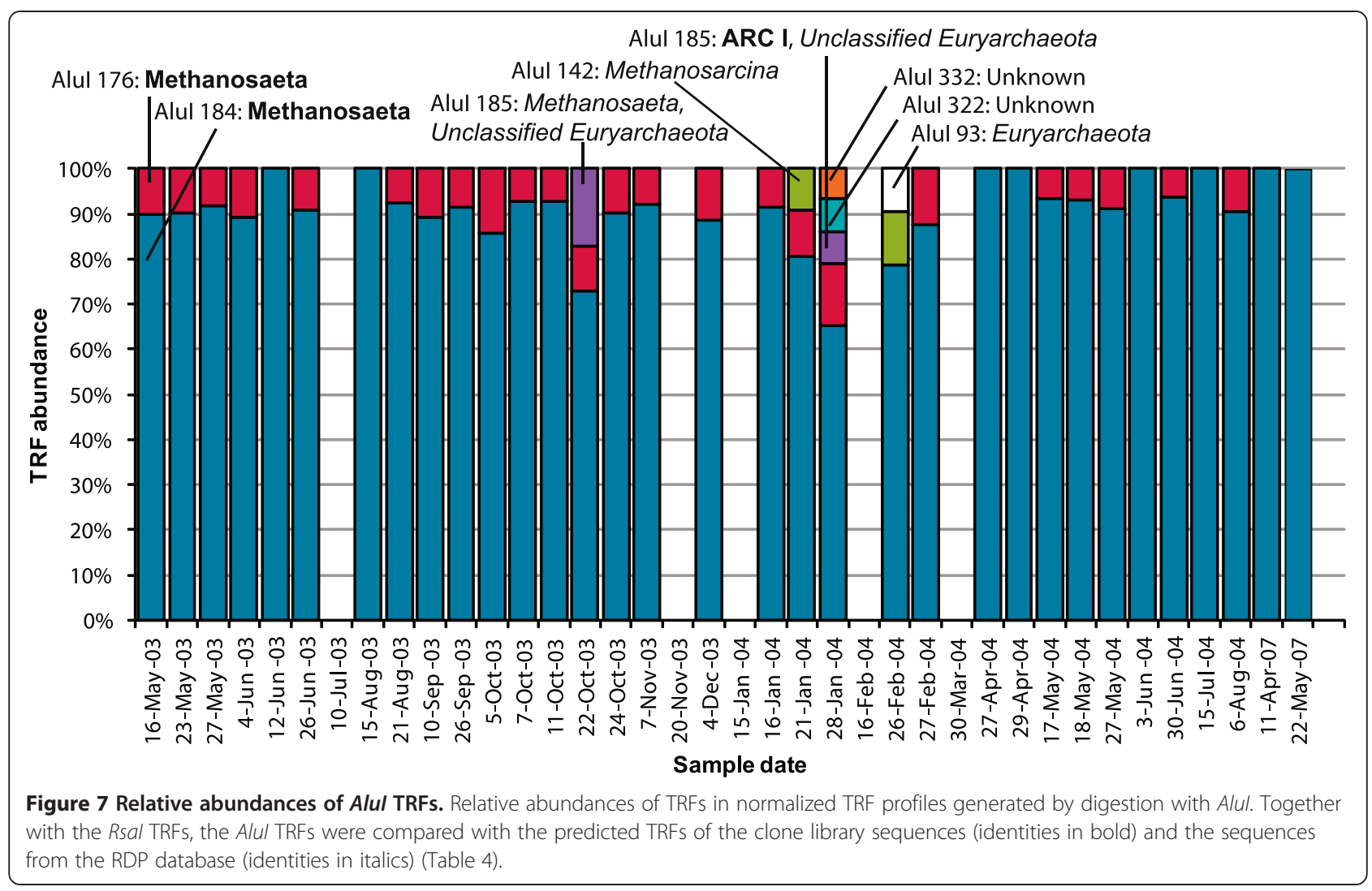

The T-RFLP time series analysis showed that the Archaea community was practically the same in most samples (Figures 7 and 8), despite variations in environmental conditions such as organic loading rate and temperature [22]. Only in a few samples more than two TRFs were observed. However, as shown in Table 3, the sensitivity of the T-RFLP analysis was low, so it is possible that there were changes in the composition of the less abundant groups of Archaea. A comparison between the observed TRF lengths and the predicted TRF lengths of the clone library sequences identified the two main TRFs as coming from Methanosaeta sequences, given the assumption that all TRFs represent the same groups of Archaea in all samples where they are observed, as discussed above. An alternative way of identifying the TRFs would be to compare the observed AluI and RsaI TRF combinations with the predicted TRF combinations from Archaea sequences in the RDP database. A comparison with 5802 Archaea $16 \mathrm{~S}$ rRNA sequences showed that sequences of Methanosaeta or other Euryarchaea would give the observed AluI and RsaI TRF combinations, but no Crenarchaeota or Thaumarchaeota sequences. In the following discussion we therefore assume that the two main TRFs come from methanogens.

Methanogens are anaerobic and the oxygen concentration in activated sludge is high. However, in the deeper parts of activated sludge flocs anoxic microenvironments can exist [38] which may allow growth of anaerobic organisms. In the activated sludge at Rya WWTP, methanogens were observed both deep within the flocs and close to the surface (Figure 11). Although exposed to oxygen, the methanogens at the surface are not necessarily inactive since methanogens have been shown to be able to maintain viability [11] and activity [39] in the presence of oxygen.

To avoid washout from the activated sludge, microorganisms need to be active and have a doubling time shorter than the sludge retention time. Pure cultures of Methanosaeta concilii have a temperature optimum at $35-40^{\circ} \mathrm{C}$ [40] and a doubling time of 4-7 days at $37^{\circ} \mathrm{C}$ [41]. The low water temperature at Rya WWTP, $10-20^{\circ} \mathrm{C}$, does not necessarily prevent activity since Methanosaeta-like species have been shown to grow at $9-14^{\circ} \mathrm{C}$ in bioreactors $[42,43]$ and dominate methanogenic cultures from rice field soil at $15^{\circ} \mathrm{C}$ [44]. The solids retention time (SRT) at Rya WWTP is typically calculated as 5-7 days and could also allow for growth of Methanosaeta-like organisms. In this study, Methanosaeta-like TRFs dominated throughout 15 months, and correlation analysis showed that some of the Methanosaeta-like TRFs increased in abundance with increasing temperature and increasing SRTs (Table 5), i.e. 


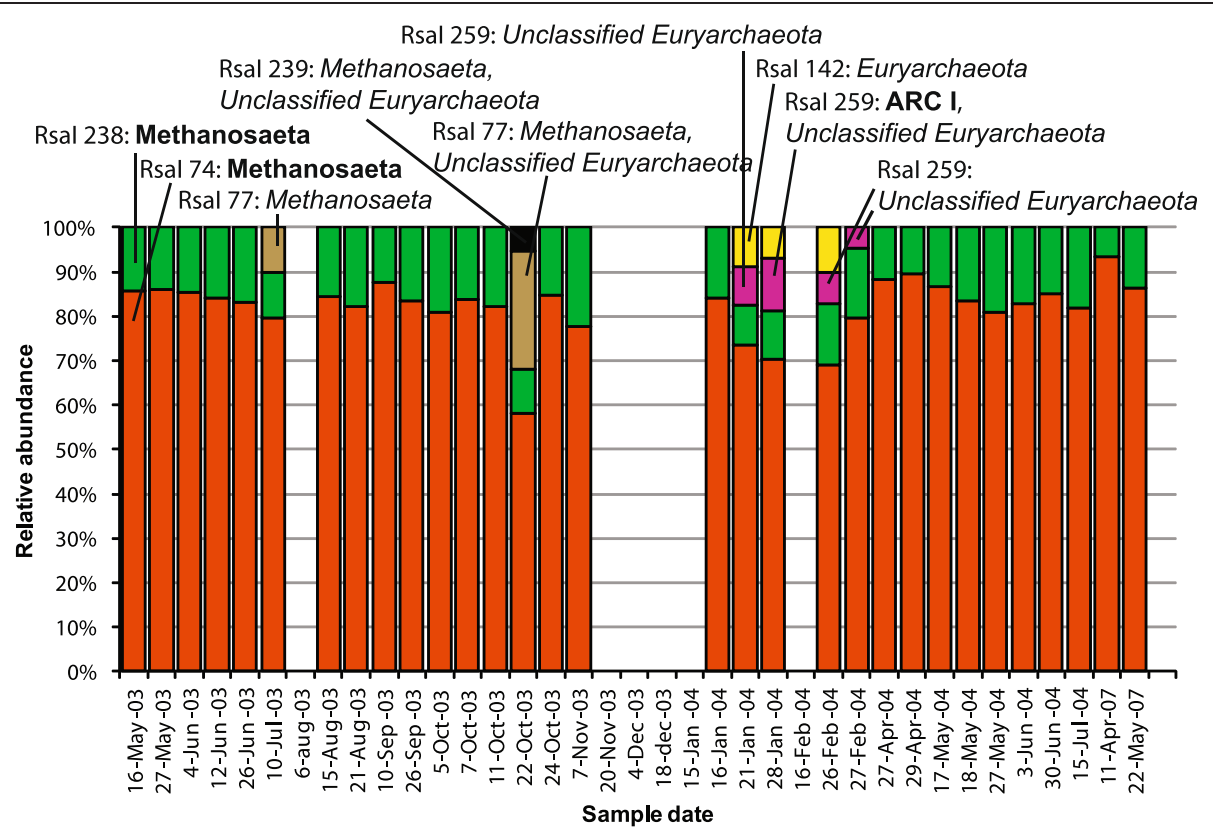

Figure 8 Relative abundances of Rsal TRFs. Relative abundances of TRFs in normalized TRF profiles generated by digestion with Rsal. Together with the Alul TRFs, the Rsal TRFs were compared with the predicted TRFs of the clone library sequences (identities in bold) and the sequences from the RDP database (identities in italics) (Table 4).

theoretically more favorable conditions. Both the constant dominance in the TRF profiles and the response to changed environmental conditions would be explained by an active population of Methanosaeta-like organisms. The detection of methanogens by FISH analysis also showed the presence of rRNA, which is expressed in active cells. However, high rRNA levels may be maintained despite inactivity. In conclusion, the activity of the Methanosaeta-like organisms is an open question.

If the Methanosaeta-like species do not grow fast enough to avoid washout, their constant presence requires that they are constantly added to the sludge. Possible sources are the influent wastewater and recycled water from an anaerobic bioreactor. By FISH analysis, Archaea was confirmed to be present in high numbers in both the anaerobic bioreactor and in the reject water (Figure 9). Thus the bioreactor might seed the activated sludge with Archaea. This is supported by the fact that a majority of the detected $16 \mathrm{~S}$ rRNA sequences cluster with sequences from anaerobic sludge (Figure 4). Furthermore, no sequences matched typical methanogens in human fecal matter, such as Methanobacter smithii and Methanosphaera stadtmanae [45], indicating that fecal matter from the influent water was not an important input to the methanogens in the activated sludge.

The second largest group in the clone library was Thermoplasmatales-related sequences affiliated with Rice Cluster III (RC-III). No cultured representative of
RC-III Archaea exists, but a study of a methanogenic enrichment culture suggests that $R C$-III Archaea are mesophilic anaerobes growing heterotrophically on peptides with a doubling time of approximately three days [27]. $R C$-III has been detected in soil [27], anaerobic bioreactors [46] and groundwater [47]. This study shows that RC-III Archaea can also be present in activated sludge.

Thermoplasmatales-related sequences of Cluster $B$ and $C$ were also found in the clone library. There are currently no cultured representatives or proposed phenotypes for these groups. Cluster $B$ and $C$ sequences have been retrieved from environments with methanogenic communities and complete or partially anoxic zones, such as water [48], landfill leachates [49], sediments [50], bioreactors [51] and the digestive tract of animals [52]. This study adds activated sludge to that list.

One sequence, clone G15, belongs to a yet undescribed lineage of Archaea: ARC I [29]. The ARC I lineage is well-represented in anaerobic bioreactors and in reactors with a high abundance of $A R C I$, the abundance of species related to $M$. concilii is low and vice versa [53], which could indicate a competition for acetate between these two lineages. The clone library in this study followed the same pattern with low abundance of ARC I and high abundance of $M$. concilii. The same pattern was also seen in the TRF profiles since the only time that the TRFs corresponding to sequence G15 was observed (January 28, 2004) the relative abundance of 
Table 4 Identification of observed TRF combinations

\begin{tabular}{|c|c|c|c|}
\hline Alul ${ }^{a}$ & Rsal $^{a}$ & Clone library ${ }^{\mathbf{b}}$ & RDP database ${ }^{c}$ \\
\hline 93 & 74 & - & Unclassified Euryarchaota \\
\hline 142 & Out of range ${ }^{d}$ & - & Methanosarcina \\
\hline 176 & 74 & Methanosaeta & Methanosaeta \\
\hline 176 & $238 / 239$ & - & Methanomicrobia \\
\hline 176 & Out of range & - & Unclassified Euryarchaota \\
\hline \multirow[t]{5}{*}{ 184/185 } & $74 / 77$ & Methanosaeta & Methanosaeta \\
\hline & & & Unclassified Euryarchaota \\
\hline & & & Thermoplasmatales \\
\hline & & & Methanomicrobiales \\
\hline & & & Methanosarcinales \\
\hline $184 / 185$ & 142 & - & Unclassified Euryarchaota \\
\hline \multirow[t]{4}{*}{$184 / 185$} & $238 / 239$ & Methanosaeta & Methanosaeta \\
\hline & & & Unclassified Euryarchaota \\
\hline & & & Methanomicrobia \\
\hline & & & Methanosarcinales \\
\hline \multirow[t]{3}{*}{ 184/185 } & 259 & $A R C I$ & Unclassified Euryarchaota \\
\hline & & & Thermoplasmatales \\
\hline & & & Methanomicrobiales \\
\hline \multirow[t]{3}{*}{ 184/185 } & Out of range & - & Unclassified Euryarchaota \\
\hline & & & Unclassified Archaea \\
\hline & & & Methanosarcinales \\
\hline \multirow[t]{2}{*}{ Out of range } & $74 / 77$ & - & Unclassified Euryarchaota \\
\hline & & & Unclassified Archaea \\
\hline \multirow[t]{2}{*}{ Out of range } & $238 / 239$ & - & Unclassified Euryarchaota \\
\hline & & & Methanosarcinales \\
\hline Out of range & 259 & - & Unclassified Euryarchaota \\
\hline
\end{tabular}

a Observed TRF combinations that are not included in the table were not found in the database nor in the clone library. ${ }^{b}$ Identification by comparison with predicted TRF lengths of clone library sequences. ${ }^{c}$ Identification by comparison with predicted TRF lengths of RDP database sequences. ${ }^{d}$ Out of range: The TRF in the database or the clone library was either shorter than 50 bases or longer than 1020 bases and would therefore not have been detected.

the TRFs associated with M. concilii had decreased to around $80 \%$.

Archaeal ammonia monooxygenase subunit A (amoA) genes have been observed in various activated sludge WWTPs $[13,15]$. One of our sequences affiliated with Crenarchaea cluster 1.1b, which includes several putative AOA [54-56]. However, it has recently been shown that not all amoA-carrying Thaumarchaeota are ammoniaoxidizing autotrophs [57]. The presence of AOA at the Rya WWTP can therefore not be confirmed, and as has been suggested for other WWTPs [14,16], AOA are most likely of minor or no importance for ammonia-oxidation at the Rya WWTP.

One clone affiliated with Crenarchaea cluster 1.3. There are no cultured representatives of cluster 1.3, but spatial co-localization [58] and a relation between the abundance of cluster 1.3 and Methanosaeta-like species has been reported [42].

In other aggregate structures, such as anaerobic sludge granules, Methanosaeta are important for structure and stability and they form dense aggregates which act as nuclei for granule formation [20]. In the activated sludge the Methanosaeta did not appear to have this function as they were mostly detected as small colonies or single cells (Figure 11) and there was no apparent difference in structure between flocs with high and low numbers of Methanosaeta.

The lowest relative abundances of the Methanosaetalike TRFs were observed in January and February 2004 (Figures 7 and 8). In October 2003 the two main Methanosaeta TRFs also decreased in relative abundance but it cannot be ruled out that the TRFs that appeared in those samples were also Methanosaeta (Table 4). The lowest water temperatures of the period were recorded during January and February 2004, which could have reduced the survival or proliferation of Methanosaeta-like species and allowed other Archaea to increase. In anaerobic sludge, a decrease in Methanosaeta abundance has been linked to granule disintegration [18,19]. Although the flocs had high shear sensitivity and a more open structure in January and February 2004 when the Methanosaeta TRFs decreased and although there was a significant negative correlation between Methanosaeta TRFs and effluent non-settleable solids (Table 6) it cannot be concluded that the Archaea are important for the floc structure. The increased shear sensitivity and changed floc structure in January and February 2004 could be due to the reduced general microbial activity, which has been shown to decrease floc stability [5]. Furthermore, increased shear sensitivity and changed floc structure was also observed from June to August 2004, after the primary settlers were bypassed, but during this period the relative abundance of the Methanosaeta TRFs was $100 \%$. Thus, if the composition of the Archaea community has any effect on floc structure or stability it is certainly only one of many other factors.

\section{Conclusions}

By sequencing and T-RFLP analysis of 16S rRNA genes and FISH we showed that Archaea were present in the activated sludge of a full-scale WWTP. The Archaea community was dominated by Methanosaeta-like species, which probably entered the sludge with a stream of recycled water from an anaerobic bioreactor. The Archaea were present both as colonies and single cells but only in low numbers, estimated as $1.6 \%$ of total cell numbers in the activated sludge. During 15 months major changes in community composition were observed twice, but in both cases the community returned to the 
Table 5 Correlations between TRF abundances and WWTP process parameters ${ }^{\text {a }}$

\begin{tabular}{|c|c|c|c|c|c|c|c|}
\hline Alul & Identity $^{b, c}$ & Observations $^{d}$ & Temp. $^{\mathrm{e}}$ & $\mathrm{SRT}^{\mathrm{f}}$ & $F / M^{g}$ & $\operatorname{COD}^{h}$ & NO23-Ni \\
\hline Alul 142 & Methanosarcina $^{b}$ & 2 & $* *$ & & & & \\
\hline Alul 176 & Methanosaeta $^{c}$ & 24 & & & $* *$ & * & \\
\hline Alul 184 & Methanosaeta ${ }^{c}$ & 33 & * & & * & & \\
\hline \multicolumn{8}{|l|}{ Rsal } \\
\hline Rsal 142 & Euryarchaeota ${ }^{\text {b }}$ & 3 & $* * *$ & & & & * \\
\hline Rsal 238 & Methanosaeta ${ }^{c}$ & 31 & * & $*$ & & & * \\
\hline Rsal 259 & $A R C 1^{c}$ & 4 & $* * *$ & & & & * \\
\hline
\end{tabular}

${ }^{a}$ The correlations are marked with asterisks corresponding to the level of statistical significance: $95 \%\left({ }^{*}\right)$, 99\% $\left({ }^{* *}\right)$ and $99.9 \%\left({ }^{* * *}\right)$. TRFs that are not included did not show any statistically significant correlation with any parameter. The WWTP process parameter data was taken from [22]. ${ }^{\mathrm{b}}$ Identification by comparison with the RDP database. ${ }^{c}$ Identification by comparison with the clone library. ${ }^{d}$ The number of times the TRF was observed. ${ }^{e}$ Water temperature $\left({ }^{\circ} \mathrm{C}\right) .{ }^{f}$ Solids retention time (days). ${ }^{g}$ Food to mass ratio ( $\left.\mathrm{g} / \mathrm{kg}^{*} \mathrm{~s}\right) .{ }^{\mathrm{h}}$ Total COD going into the activated sludge tanks $(\mathrm{g} / \mathrm{s}) .{ }^{\mathrm{i}}$ Nitrite/nitrate levels going in to the activated sludge tanks ( $\left.\mathrm{g} / \mathrm{s}\right)$.

previous composition. Even in samples collected three years apart the main part of the community remained the same according to T-RFLP data. We now know that Archaea can constitute a small but constant and integral part of the activated sludge and that it can therefore be useful to include Archaea in future studies of sludge or floc properties.

\section{Methods}

\section{Sample collection}

The Rya WWTP in Göteborg, Sweden, treats domestic and industrial wastewater serving approximately 850,000 population equivalents. The plant uses pre-denitrification in an activated sludge system and post-nitrifying trickling filters for biological nitrogen removal. Typical sludge age is 5-7 days. A detailed description of the design and operating parameters of the Rya WWTP can be found elsewhere [21]. Samples were collected at the end of the aerated basins. $50 \mathrm{~mL}$ of sample was centrifuged and the resulting pellet was stored at $-20^{\circ} \mathrm{C}$ within $1.5 \mathrm{~h}$ from collection. For the T-RFLP time series sludge samples were collected between May 16, 2003 and August 6,
2004. The frequency of sample collection varied between days and weeks. One sample was collected May 22, 2007 for T-RFLP and clone library analysis and an additional sample was collected December 12, 2007 for FISH analysis. At all sample times the treatment plant was operated the same way except for four months, May 24 to September 24, 2004, when the primary settlers were bypassed. Table 1 shows average values for some process and sludge parameters during 2003, 2004 and 2007. The software PAST (version 2.01) [59] was used for statistical analysis. The data was not normally distributed and analysis of variance was therefore carried out using the nonparametric Kruskal-Wallis test.

\section{DNA extraction}

DNA was extracted using Power Soil DNA Extraction Kit (MoBio Laboratories). The frozen sludge pellets were thawed, $15 \mathrm{~mL}$ sterile water was added and the samples were homogenized by $6 \mathrm{~min}$ of mixing in a BagMixer 100 MiniMix (Interscience). Water was removed by centrifugation and DNA was extracted from $0.25 \mathrm{~g}$ of

Table 6 Correlations between TRF abundances and sludge and effluent water parameters ${ }^{\text {a }}$

\begin{tabular}{|c|c|c|c|c|c|c|c|}
\hline Alul & Identity ${ }^{b, c}$ & Observations $^{d}$ & $\mathrm{SSVl}^{\mathrm{e}}$ & Shear sensitivity ${ }^{f}$ & EPS protein ${ }^{g}$ & EPS carb. ${ }^{h}$ & Effluent NSS \\
\hline Alul 142 & Methanosarcina $^{b}$ & 2 & & & & & $* * *$ \\
\hline Alul 176 & Methanosaeta ${ }^{c}$ & 24 & & & & & \\
\hline Alul 184 & Methanosaeta $^{c}$ & 33 & & & & $* * *$ & $* * *$ \\
\hline Alul 185 & $A R C I^{C}$ & 2 & & & * & $* * *$ & \\
\hline \multicolumn{8}{|l|}{ Rsal } \\
\hline Rsal 74 & Methanosaeta $^{c}$ & 31 & & & * & $* * *$ & \\
\hline Rsal 142 & Euryarchaeota ${ }^{b}$ & 3 & & & $* *$ & $* * *$ & $* * *$ \\
\hline Rsal 238 & Methanosaeta $^{c}$ & 31 & & & & & $* * *$ \\
\hline Rsal 259 & $A R C I^{c}$ & 4 & & & $* *$ & $* * *$ & $* * *$ \\
\hline
\end{tabular}

${ }^{a}$ The correlations are marked with asterisks corresponding to the level of statistical significance: $95 \%\left({ }^{*}\right), 99 \%\left({ }^{* *}\right)$ and $99.9 \%\left({ }^{* *}\right)$. TRFs that are not included did not show any statistically significant correlation with any parameter. The sludge and effluent water parameter data was taken from [22]. ${ }^{\mathrm{b}}$ Identification by comparison with the RDP database. ${ }^{c}$ Identification by comparison with the clone library. ${ }^{\mathrm{d}}$ The number of times the TRF was observed. ${ }^{\text {e }}$ Standardized sludge volume index (ml/g). ${ }^{\mathrm{f}}$ Shear sensitivity (arbitrary units). ${ }^{\mathrm{g}}$ EPS protein (mg/gMLSS). ${ }^{\mathrm{h}}$ EPS carbohydrates (mg/gMLSS). ${ }^{\mathrm{i}}$ Effluent non-settleable solids (mg/l). 


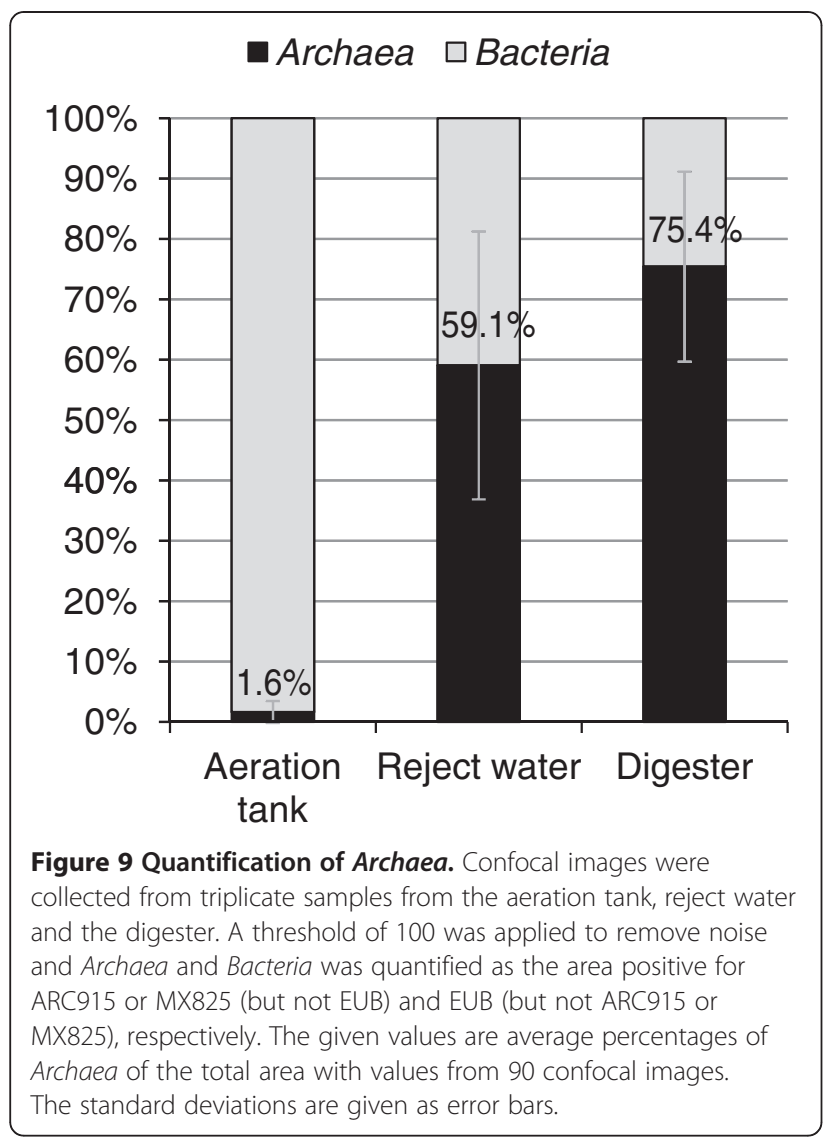

homogenized sludge pellet according to the manufacturer's instructions.

\section{PCR}

Archaeal 16S rRNA genes were amplified using HotStarTaqPlus PCR kit (Qiagen) and Archaea-specific primers Arch18F (TTCCGGTTGATCCYGCC) and Arch959R (YCCGGCGTTGAMTCCAAT) (Thermo
Fisher Scientific). PCR reactions were carried out in a total volume of $20 \mu \mathrm{l}$ in the provided PCR buffer with $0.5 \mathrm{U}$ HotStarTaq Plus, $200 \mu \mathrm{M}$ dNTP mix, $0.1 \mu \mathrm{M}$ of each primer and 2-5 ng DNA. The primers were based on previously published sequences Arch958R and Arch21F [60]. The reverse primer Arch958R was shortened to remove a 4-bases self complementary 3'end (AATT). The forward primer Arch21F was shortened to match the new annealing temperature of the reverse primer. The cycle profiles had an initial $5 \mathrm{~min}$ at $95^{\circ} \mathrm{C}$ for Taq polymerase activation followed by denaturation at $94^{\circ} \mathrm{C}$ for $1 \mathrm{~min}$, annealing at $58^{\circ} \mathrm{C}$ for $30 \mathrm{~s}$ and elongation at $72^{\circ} \mathrm{C}$ for $1 \mathrm{~min}$. The annealing temperature was decreased $1^{\circ} \mathrm{C}$ every 3 cycles until reaching $55^{\circ} \mathrm{C}$ where the number of cycles was 30 . The reactions were ended with a final elongation step at $72^{\circ} \mathrm{C}$ for $7 \mathrm{~min}$.

\section{Cloning}

The PCR-products of nine PCR replicates, generated from two DNA extraction replicates, were pooled and purified using Qiagen MinElute PCR Purification Kit (Qiagen). $8 \mathrm{ng}$ and $15 \mathrm{ng}$ of purified PCR-product were ligated into the plasmid vector pCR 4 TOPO (Invitrogen) in duplicate reactions. One Shot DH5alpha-T1R competent Escherichia coli cells (Invitrogen) were transformed with the vector constructs according to the manufacturer's instructions in two separate reactions. The transformed cells were plated on LB-agar plates with $50 \mu \mathrm{g} / \mathrm{ml}$ Kanamycin and incubated at $37^{\circ} \mathrm{C}$ over night. 95 cloned sequences were amplified directly from transformed single colonies from the two cloning reactions by PCR using the vector specific primers T3 (ATTAACCCTCACTAAAGGGA) and T7 (TAATAC GACTCACTATAGGG). The bacterial cells were lysed by five minutes incubation at $94^{\circ} \mathrm{C}$ followed by PCRcycles as described above but with a starting annealing temperature of $57^{\circ} \mathrm{C}$.

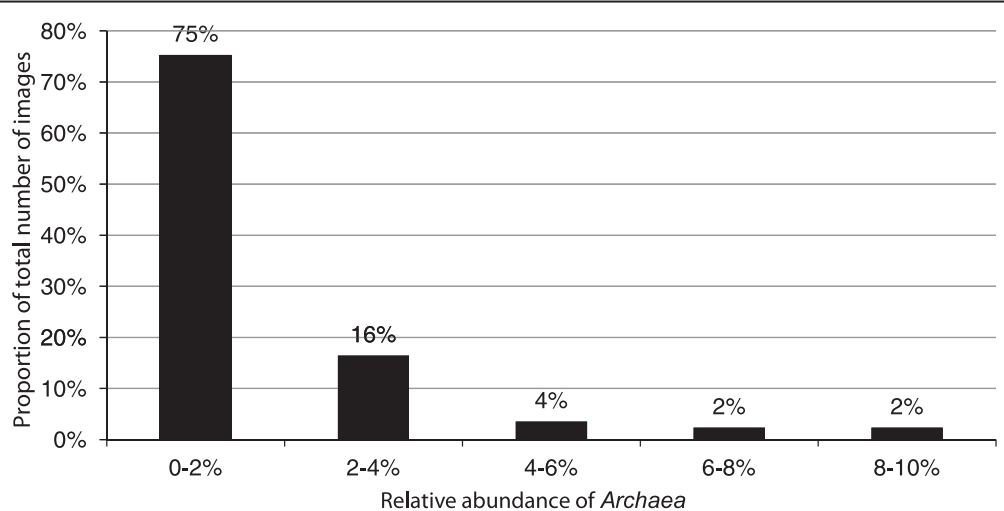

Figure 10 Distribution of Archaea. The proportion of the total number of confocal images for different intervals of Archaea abundance in triplicate samples from the aeration tank. 

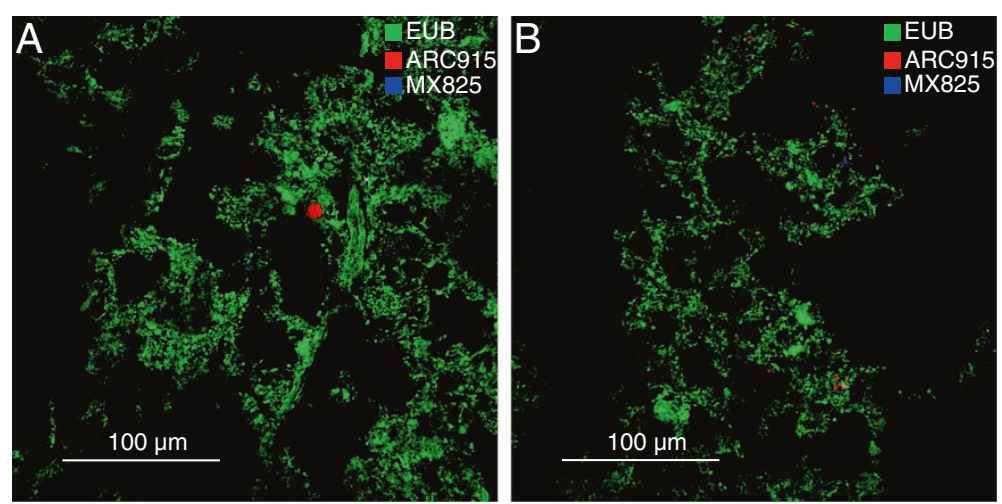

Figure 11 FISH images with probes for Bacteria, Archaea and Methanosaeta. Confocal images of activated sludge samples hybridized with probes EUB, ARC915 and MX825, which are specific for Bacteria, Archaea and Methanosaeta, respectively. The images were generated using Daime 1.1 [34] with an applied threshold of 50.

\section{Sequencing and sequence analysis}

Cloned sequences were sequenced from both ends using Big Dye Sequencing Kit (Applied Biosystems) and primers T3 and T7 as sequencing primers. Sequence data was generated by capillary gel electrophoresis (3730 DNA analyzer, Applied Biosystems). Raw data sequences were manually inspected using SeqScape (Applied Biosystems). Sequences sequenced from different ends of the PCR-product were aligned using BioEdit (version 5.0.9) [61]. Consensus sequences were generated for 82 clones with overlaps between the 5' and 3' end sequences ranging from 80 to 496 bases.

The sequences were aligned using the alignment tool of the SILVA rRNA database [26] and checked for chimeras using the Bellerophon server [62]. The sequences were also aligned with a reference E. Coli sequence, accession number U00096, and checked for chimeras using Mallard [63]. No chimeric sequences were detected with either of the two methods.

The similarity between the $16 \mathrm{~S}$ rRNA gene sequences was determined by generating a similarity matrix using the DNADIST program in the PHYLIP package [64]. The sequences were then assigned to OTUs based on different similarity thresholds. For Bacteria, 16S rRNA gene sequence similarities of $80 \%, 90 \%, 95 \%$ and $98.7 \%$ approximately represent the division in phylum, family/ class, genus and species levels, respectively [23,24], and we use the same criteria for Archaea. Accumulation curves were constructed by plotting the number of OTUs found in a given number of clones versus the number of clones. The lower bound of the richness of the community was estimated with the nonparametric estimator CHAO1 using the software SPADE (version 3.1; Institute of Statistics, National Tsing Hua University [http://chao.stat.nthu.edu.tw]). The CHAO1 estimator was chosen according to the properties of the data set following the recommendations in the SPADE documentation.
A Pareto-Lorenz evenness curve $[65,66]$ was used to illustrate and quantify the evenness of the Archaea community. The sequences were divided in OTUs based on a sequence similarity threshold of $98.7 \%$ and ranked from high to low, based on their abundance. The cumulative proportion of OTU abundances (Y) was then plotted against the cumulative proportion of OTUs $(\mathrm{X})$ resulting in a concave curve starting at $(\mathrm{X}, \mathrm{Y})=(0 \%, 0 \%)$ and ending in $(X, Y)=(100 \%, 100 \%)$. The Fo index is the horizontal $y$-axis projection on the intercept with the vertical $20 \% \mathrm{x}$-axis line, i.e. the combined relative abundance of $20 \%$ of the OTUs. In a community with high evenness all or most OTUs are equally abundant which results in a Pareto-Lorenz curve close to a straight line of $45^{\circ}$. The Fo index for such a community is close to $20 \%$. Specialized communities with one or a few dominating OTUs generate concave curves with high Fo indices.

All sequences were compared with available sequences in the GenBank nucleotide database using BLAST (Basic Local Alignment Search Tool) [25] August 22, 2011. The search tool of the SILVA rRNA database [26] was also used. However, matching sequences in GenBank always had higher similarities than the best matches from SILVA.

TRF lengths were predicted for all clone library sequences. The sequences all started 50-100 bases away from the forward primer so the TRF lengths were predicted by alignment with a reference sequence containing the primer site and assuming that there were no inserts or deletions between the primer and position 100. If the reference sequence had a restriction enzyme cut site preceding the first bases of the clone library sequence, the TRF for the clone library sequence could not be predicted.

25 sequences representing the 25 OTUs obtained by applying a sequence similarity threshold of $98.7 \%$ were 
subjected to phylogenetic analysis. The cloned sequences were aligned together with reference sequences representing known and proposed novel Archaea divisions using the alignment tool of the SILVA rRNA database [26]. To make all sequences of equal length the resulting alignment was trimmed using BioEdit [61]. Phylogenetic tree analysis was carried out using the PHYLIP package [64]. Bootstrap analysis was carried out by generating 100 datasets using the program seqboot. The 100 datasets were analyzed by the maximum likelihood method using dnaml and 100 trees were created. The sequence of the bacteria Aquifex Pyrophilus was used as outgroup. A majority rule consensus tree was constructed from the 100 trees using consense. The branching of the consensus tree was seen as an estimate of the true tree. Finally, the original alignment was analyzed by maximum likelihood using dnaml but instead of searching for the best tree, the sequences were fitted to the consensus tree. In the resulting tree, the branching was derived from the bootstrap analysis, and the branch lengths from the maximum likelihood analysis.

\section{Nucleotide sequence accession numbers}

The partial 16S rRNA gene sequences obtained in this study are available in GenBank under accession numbers JQ062987 and HM639782 to HM639862.

\section{T-RFLP analysis}

Sludge sample collection and DNA extraction was carried out as described above. Archaeal 16S rRNA genes were amplified as described above but with the forward primer Arch18F labeled with the fluorescent dye 6 - carboxyfluorescein. Three PCR reactions were prepared from each sludge sample. The PCR products were purified using the Agencourt AMPure system (Beckman Coulter) and digested with 10 units of restriction enzyme at $37^{\circ} \mathrm{C}$ for at least 16 hours. Restriction enzymes AluI and RsaI were used in separate reactions. The restriction digests were purified and analyzed by capillary gel electrophoresis (3730 DNA Analyzer, Applied Biosystems). The size standard LIZ1200 (Applied Biosystems) was used for fragment size determination.

The software Genemapper (Applied Biosystems) was used to quantify the electropherogram data and to generate the TRF profiles. Peaks from fragments of size 50-1020 bases with a height above 50 fluorescent units were analyzed. The total fluorescence of a sample was defined as the sum of the heights of all the peaks in the profile and was interpreted as a measure of the amount of DNA that was loaded on the capillary gel. Only samples with at least two of the three TRF profiles with a total fluorescence above 500 fluorescent units were considered for further analysis. The two profiles with the highest total fluorescence were chosen from each sample. The TRFs of the two profiles were aligned using a moving average procedure [67] and then checked manually for errors. The two profiles were then normalized as described by Dunbar et al [68] and combined to a single consensus profile by taking the average size, height and areas of the fragments present in both. Consensus profiles with a low total fluorescence, i.e. where low amounts of DNA had been loaded on the gel, were excluded from the subsequent analysis to avoid excessive normalization. 32 and 33 consensus TRF profiles, for the RsaI and AluI analysis, respectively, were normalized and aligned as described above. The TRFs that were removed by normalization constituted only a minor part of the TRF profiles, on average $2 \pm 3 \%$ and $1 \pm 2 \%$ of the total fluorescence in the AluI and RsaI profiles, respectively.

The dynamics of the Archaea community were evaluated by pair-wise comparisons of TRF profiles using the Bray-Curtis distance coefficient (described in e.g. [69]). The Bray-Curtis distance coefficient is calculated using the relative abundances of the TRFs. All TRF profiles were compared with the TRF profile of the first sample in the time series.

Possible identities of the TRFs were investigated as follows. The Virtual digest tool at the MICA website [70] was used to generate a list of 5802 sequences from the RDP database (RDP (R10, U26) 70108 16S rRNA Archaeal) that matched the primers $18 \mathrm{~F}$ and $959 \mathrm{R}$. For each sequence the predicted TRF lengths after digestion with RsaI and AluI were given. Sequences in the list that had both AluI and RsaI TRFs that matched the TRFs in the observed TRF profiles were selected. The selection was done using a Visual Basic macro for Microsoft Office Excel (Microsoft Corporation) (available from corresponding author). The sequences of the possible

Table 7 FISH probes targeting 16S rRNA and the hybridization conditions used in this study

\begin{tabular}{llcccccc}
\hline Probe & \multicolumn{1}{c}{ Target } & Target sequence & E.coli positions & Formamide (\%) & NaCl (mM) & Fluorophore & Reference \\
\hline ARC915 & Archaea & GTGCTCCCCCGCCAATTCCT & $915-934$ & 35 & 70 & Cy5 & [73], [74] \\
MX825 & Methanosaetaceae & TCGCACCGTGGCCGACACCTAGC & $825-845$ & 50 & 18 & Cy3 & [73], [74] \\
EUB338 & Bacteria & GCTGCCTCCCGTAGGAGT & $338-355$ & 35 & 70 & Alexa & [75] \\
EUB338 II & Bacteria & GCAGCCACCCGTAGGTGT & $338-355$ & 35 & 70 & Alexa & {$[75]$} \\
EUB338 III & Bacteria & GCTGCCACCCGTAGGTGT & $338-355$ & 35 & 70 & Alexa & [75] \\
\hline
\end{tabular}


candidates were obtained from Genbank and fed into the RDP classifier [71]. Each observed TRF could then be assigned various possible taxonomic classes.

The relative abundance of the TRFs was calculated as the peak height of the TRF divided by the total fluorescence of the TRF profile. The Pearson's product momentum correlation coefficient was used to estimate the linear correlation between relative abundances of TRFs, process parameters and sludge properties. For details on the process data and sludge properties measurements, see [22]. To determine the statistical significance of the correlation a t-test was carried out.

\section{Fluorescence in situ hybridization}

Samples were collected from the anaerobic digester, the reject water and the aeration tank and fixed in $4 \%$ paraformaldehyde at $4^{\circ} \mathrm{C}$ for $3 \mathrm{~h}$. The fixed samples were washed with phosphate-buffered saline (PBS) and stored in PBS-ethanol $(1: 1)$ at $-20^{\circ} \mathrm{C}$ until analysis. The hybridization protocol was based on previously published protocols [72]. In short, 3 aliquots of $3 \mu \mathrm{l}$ fixed sample were applied to microscope slides, air-dried and dehydrated by incubation in ethanol. $30 \mu \mathrm{l}$ of hybridization buffer containing probe and formamide was applied to each aliquot and in situ hybridization with labeled rRNA-targeted probes was performed in humidity chambers at $46^{\circ} \mathrm{C}$ for $2 \mathrm{~h}$. The slides were washed with washing buffer, rinsed in ice-cold water and air-dried. To prevent fluorochrome bleaching, all slides were mounted with Citifluor AF1 (Citifluor Ltd, London, UK). Target sequences, hybridization conditions, and references for the probes used in this study are listed in Table 7. All fluorescent probes were obtained from Thermo Hybaid (Interactiva Division, Ulm, Germany). Fluorescent probes were labeled at the $5^{\prime}$ end with indocarbocyanine (Cy3), indodicarbocyanine (Cy5) or Alexa Fluor 488.

\section{Quantification using FISH}

Confocal images were collected with a Bio-Rad Radiance 2000 MP microscope (Bio-Rad, Hemel Hempstead, UK) using the $\mathrm{Ar} \mathrm{Kr} / \mathrm{Ar}(488 \mathrm{~nm}), \mathrm{GHe} / \mathrm{Ne}(543 \mathrm{~nm})$ and Red Diode $(638 \mathrm{~nm})$ lasers and the bundled software LaserSharp 2000. Settings: 40xOil inverted objective (Nikon Eclipse TE300 Corp, Tokyo, Japan), Image size: $512 \times 512$ pixel, XY-pixel: $0.60 \mu \mathrm{m}$, Kalman filtration $(n=3)$. For each sample, three replicates were analyzed. For each replicate, images were collected from 10 fields of view, chosen by arbitrary movements in the $\mathrm{X}$-Y-direction. For each field of view, 3 images were collected at $4 \mu \mathrm{m}$ intervals in the Z-direction. In total 90 images were collected per sample.

The images were analyzed using Image) (version $1.44 \mathrm{p}$, Wayne Rasband, National Institute of Health, Bethesda, MD, USA, available at the public domain at http://rsb.info.nih.gov/ij/index.html). A threshold of 100 was applied to remove noise. Images were converted to binary images and image calculations using the AND and OR functions were applied as follows. Cells stained with both EUBmix and either one of ARC915 or MX825 were removed from further analysis. The combined area of Archaea and Bacteriapositive cells, the total area with a signal, was calculated for all 90 images and all 3 probes. ARC915, although designed as a universal Archaea probe did not cover all MX825 positive cells. The total area for Archaea was therefore counted as ARC915 positive cells plus MX825 positive cells not covered by ARC915. The relative abundance of Archaea was then calculated as the total area of Archaea divided by the combined area of Archaea and Bacteria. To analyze only images of flocs, and not dispersed cells, images with a total area (both Bacteria and Archaea) lower than 1000 pixels were removed.

Daime 1.1 [34] was used to generate images with all three probes used in the FISH analysis.

\section{Acknowledgements}

We thank the staff at Gryaab AB for assistance in obtaining samples and for providing data. We also thank The SWEGENE Göteborg Genomics Core Facility platform, which was funded by a grant from the Knut and Alice Wallenberg Foundation. This work was funded by a research grant from FORMAS.

\section{Author details}

'Department of Civil and Environmental Engineering, Water Environment Technology, Chalmers University of Technology, Gothenburg, Sweden. ${ }^{2}$ Department of Chemistry and Molecular Biology, Microbiology, University of Gothenburg, Gothenburg, Sweden.

\section{Authors' contributions}

NJF, MH and BMW conceived and designed the study. NJF and BMW collected samples. NJF carried out the experiments, evaluated the results and drafted the manuscript. BMW and MH provided guidance during the whole study and revised the manuscript. All authors read and approved the final manuscript.

Received: 30 January 2012 Accepted: 11 July 2012 Published: 11 July 2012

\section{References}

1. Wilén B-M, Onuki M, Hermansson M, Lumley D, Mino T: Influence of flocculation and settling properties of activated sludge in relation to secondary settler performance. Water Sci Technol 2006, 54:147-155.

2. Klausen MM, Thomsen TR, Nielsen JL, Mikkelsen LH, Nielsen PH: Variations in microcolony strength of probe-defined bacteria in activated sludge flocs. FEMS Microbiol Ecol 2004, 50:123-132.

3. Morgan-Sagastume F, Larsen P, Nielsen JL, Nielsen PH: Characterization of the loosely attached fraction of activated sludge bacteria. Water Res 2008, 42:843-854.

4. Wilén B-M, Onuki M, Hermansson M, Lumley D, Mino T: Microbial community structure in activated sludge floc analysed by fluorescence in situ hybridization and its relation to floc stability. Water Res 2008, 42:2300-2308.

5. Wilén B-M, Nielsen JL, Keiding K, Nielsen PH: Influence of microbial activity on the stability of activated sludge flocs. Colloids Surf B Biointerfaces 2000, 18:145-156.

6. Wilén B-M, Jin B, Lant P: Relationship between flocculation of activated sludge and composition of extracellular polymeric substances. Water Sci Technol 2003, 47:95-103. 
7. Wilén B-M, Jin B, Lant P: The influence of key chemical constituents in activated sludge on surface and flocculating properties. Water Res 2003, 37:2127-2139

8. Figuerola ELM, Erijman L: Bacterial taxa abundance pattern in an industrial wastewater treatment system determined by the full rRNA cycle approach. Environ Microbiol 2007, 9:1780-1789.

9. Juretschko S, Loy A, Lehner A, Wagner M: The Microbial Community Composition of a Nitrifying-Denitrifying Activated Sludge from an Industrial Sewage Treatment Plant Analyzed by the Full-Cycle rRNA Approach. Syst Appl Microbiol 2002, 25:84-99.

10. Hagman M, Nielsen JL, Nielsen PH, Jansen JL: Mixed carbon sources for nitrate reduction in activated sludge-identification of bacteria and process activity studies. Water Res 2008, 42:1539-1546.

11. Gray ND, Miskin IP, Kornilova O, Curtis TP, Head IM: Occurrence and activity of Archaea in aerated activated sludge wastewater treatment plants. Environ Microbiol 2002, 4:158-168.

12. Sánchez O, Garrido L, Forn I, Massana R, Maldonado Ml, Mas J: Molecular characterization of activated sludge from a seawater-processing wastewater treatment plant. Microb Biotechnol 2011, 4:628-642.

13. Park H-D, Wells GF, Bae H, Criddle CS, Francis CA: Occurrence of AmmoniaOxidizing Archaea in Wastewater Treatment Plant Bioreactors. Appl Environ Microbiol 2006, 72:5643-5647.

14. Wells GF, Park HD, Yeung CH, Eggleston B, Francis CA, Criddle CS: Ammonia-oxidizing communities in a highly aerated full-scale activated sludge bioreactor: betaproteobacterial dynamics and low relative abundance of Crenarchaea. Environ Microbio/ 2009, 11:2310-2328.

15. Zhang T, Jin T, Yan Q, Shao M, Wells G, Criddle C, Fang HHP: Occurrence of ammonia-oxidizing Archaea in activated sludges of a laboratory scale reactor and two wastewater treatment plants. J Appl Microbiol 2009, 107:970-977.

16. Daims H, Lücker S, Mussman M, Brito I, Spieck E, Head IM, Le Paslier D, Wagner M: Ammonia-oxidizing Archaea and nitrite-oxidizing Nitrospira in wastewater treatment plants: New insights based on molecular tools and environmental genomics. In ASPD5 specialist conference: Microbial Population Dynamics in Biological Wastewater Treatment. Aalborg, Denmark: IWA; 2009:80-83.

17. Jun HB, Park SM, Park NB, Lee SH: Nitrogen removal and sludge reduction in a symbiotic activated sludge system between anaerobic archaea and bacteria. Water Sci Technol 2004, 50:189-197.

18. Enright A-M, Collins G, O'Flaherty V: Temporal microbial diversity changes in solvent-degrading anaerobic granular sludge from low-temperature $\left(15^{\circ} \mathrm{C}\right)$ wastewater treatment bioreactors. Syst Appl Microbiol 2007, 30:471-482.

19. McKeown RM, Scully C, Enright A-M, Chinalia FA, Lee C, Mahony T, Collins G, O'Flaherty V: Psychrophilic methanogenic community development during long-term cultivation of anaerobic granular biofilms. ISME J 2009, 3:1231-1242.

20. Zheng $D$, Angenent LT, Raskin L: Monitoring granule formation in anaerobic upflow bioreactors using oligonucleotide hybridization probes. Biotechnol Bioeng 2006, 94:458-472.

21. Wilén B-M, Lumley D, Mattsson A, Mino T: Dynamics in Flocculation and Settling Properties Studied at a Full-Scale Activated Sludge Plant. Water Environ Res 2010, 82:155-168.

22. Wilén B-M, Lumley D, Mattsson A, Mino T: Relationship between floc composition and flocculation and settling properties studied at a full scale activated sludge plant. Water Res 2008, 42:4404-4418.

23. Schloss PD, Handelsman J: Status of the Microbial Census. Microbiol Mol Biol Rev 2004, 68:686-691.

24. Stackebrandt E, Ebers J: Taxonomic parameters revisited: tarnished gold standards Microbiology Today. 2006:152-155. November.

25. Altschul SF, Gish W, Miller W, Myers EW, Lipman DJ: Basic Local Alignment Search Tool. J Mol Biol 1990, 215:403-410.

26. Pruesse E, Quast C, Knittel K, Fuchs BM, Ludwig W, Peplies Jr, Glöckner FO: SILVA: a comprehensive online resource for quality checked and aligned ribosomal RNA sequence data compatible with ARB. Nucleic Acids Res 2007, 35:7188-7196.

27. Kemnitz D, Kolb S, Conrad R: Phenotypic characterization of Rice Cluster III archaea without prior isolation by applying quantitative polymerase chain reaction to an enrichment culture. Environ Microbiol 2005, 7:553-565.
28. Grosskopf R, Stubner S, Liesack W: Novel Euryarchaeotal Lineages Detected on Rice Roots and in the Anoxic Bulk Soil of Flooded Rice Microcosms. Appl Environ Microbiol 1998, 64:4983-4989.

29. Chouari R, Le Paslier D, Daegelen P, Ginestet P, Weissenbach J, Sghir A Novel predominant archaeal and bacterial groups revealed by molecular analysis of an anaerobic sludge digester. Environ Microbiol 2005, 7:1104-1115.

30. DeLong EF: Everything in moderation: Archaea as 'non-extremophiles'. Curr Opin Genet Dev 1998, 8:649-654.

31. Jurgens G, Glockner F-O, Amann R, Saano A, Montonen L, Likolammi M, Munster U: Identification of novel Archaea in bacterioplankton of a boreal forest lake by phylogenetic analysis and fluorescent in situ hybridization1. FEMS Microbiol Ecol 2000, 34:45-56.

32. Kaplan CW, Kitts CL: Variation between observed and true Terminal Restriction Fragment length is dependent on true TRF length and purine content. J Microbiol Methods 2003, 54:121-125.

33. Kitts CL: Terminal restriction fragment patterns: A tool for comparing microbial communities and assessing community dynamics. Curr Issues Intest Microbiol 2001, 2:17-25.

34. Daims $H$, Lucker $S$, Wagner M: daime, a novel image analysis program for microbial ecology and biofilm research. Environ Microbiol 2006, 8:200-213.

35. Collins G, O'Connor L, Mahony T, Gieseke A, de Beer D, O'Flaherty V: Distribution, Localization, and Phylogeny of Abundant Populations of Crenarchaeota in Anaerobic Granular Sludge. Appl Environ Microbiol 2005, 71:7523-7527.

36. Akarsubasi AT, Eyice O, Miskin I, Head IM, Curtis TP: Effect of Sludge Age on the Bacterial Diversity of Bench Scale Sequencing Batch Reactors. Environ Sci Technol 2009, 43:2950-2956.

37. Davenport RJ, Curtis TP, Goodfellow M, Stainsby FM, Bingley M: Quantitative Use of Fluorescent In Situ Hybridization To Examine Relationships between Mycolic Acid-Containing Actinomycetes and Foaming in Activated Sludge Plants. Appl Environ Microbiol 2000, 66:1158-1166

38. Schramm A, Santegoeds CM, Nielsen HK, Ploug H, Wagner M, Pribyl M, Wanner J, Amann R, de Beer D: On the Occurrence of Anoxic Microniches, Denitrification, and Sulfate Reduction in Aerated Activated Sludge. Appl Environ Microbiol 1999, 65:4189-4196.

39. Hirasawa JS, Sarti A, Del Aguila NKS, Varesche MBA: Application of molecular techniques to evaluate the methanogenic archaea and anaerobic bacteria in the presence of oxygen with different COD:Sulfate ratios in a UASB reactor. Anaerobe 2008, 14:209-218.

40. Kendall MM, Boone DR: The Order Methanosarcinales. In The Prokaryotes. 3rd edition. Edited by Dworkin M, Falkow S, Rosenberg E, Schleifer K-H, Stackebrandt E. Singapore: Springer Science+Business Media, LLC; 2006.

41. Garcia J-L, Patel BKC, Ollivier B: Taxonomic, Phylogenetic, and Ecological Diversity of Methanogenic Archaea. Anaerobe 2000, 6:205-226.

42. Enright A-M, McGrath V, Gill D, Collins G, O'Flaherty V: Effect of seed sludge and operation conditions on performance and archaeal community structure of low-temperature anaerobic solvent-degrading bioreactors. Syst Appl Microbiol 2009, 32:65-79.

43. McHugh S, Carton M, Mahony T, O'Flaherty V: Methanogenic population structure in a variety of anaerobic bioreactors. FEMS Microbiol Lett 2003, 219:297-304.

44. Chin K-J, Lukow T, Stubner S, Conrad R: Structure and function of the methanogenic archaeal community in stable cellulose-degrading enrichment cultures at two different temperatures $\left(15\right.$ and $\left.30^{\circ} \mathrm{C}\right)$. FEMS Microbiol Ecol 1999, 30:313-326.

45. Mihajlovski A, Doré J, Levenez F, Alric M, Brugère J-F: Molecular evaluation of the human gut methanogenic archaeal microbiota reveals an ageassociated increase of the diversity. Environmental Microbiology Reports 2010, 2:272-280.

46. Nunoura T, Oida H, Miyazaki J, Miyashita A, Imachi H, Takai K: Quantification of mcrA by fluorescent PCR in methanogenic and methanotrophic microbial communities. FEMS Microbiol Ecol 2008, 64:240-247.

47. Shimizu S, Akiyama M, Ishijima Y, Hama K, Kunimaru T, Naganuma T: Molecular characterization of microbial communities in fault-bordered aquifers in the Miocene formation of northernmost Japan. Geobiology 2006, 4:203-213.

48. Watanabe K, Kodama Y, Hamamura N, Kaku N: Diversity, Abundance, and Activity of Archaeal Populations in Oil-Contaminated Groundwater 
Accumulated at the Bottom of an Underground Crude Oil Storage Cavity. Appl Environ Microbiol 2002, 68:3899-3907.

49. Huang L-N, Chen Y-Q, Zhou H, Luo S, Lan C-Y, Qu L-H: Characterization of methanogenic Archaea in the leachate of a closed municipal solid waste landfill. FEMS Microbiol Ecol 2003, 46:171-177.

50. Nold SC, Zajack HA, Biddanda BA: Eukaryal and archaeal diversity in a submerged sinkhole ecosystem influenced by sulfur-rich, hypoxic groundwater. Journal of Great Lakes Research 2010, 36:366-375.

51. Godon JJ, Zumstein E, Dabert P, Habouzit F, Moletta R: Molecular microbial diversity of an anaerobic digestor as determined by small-subunit rDNA sequence analysis. Appl Environ Microbiol 1997, 63:2802-2813.

52. Egert M, Wagner B, Lemke T, Brune A, Friedrich MW: Microbial Community Structure in Midgut and Hindgut of the Humus-Feeding Larva of Pachnoda ephippiata (Coleoptera: Scarabaeidae). Appl Environ Microbiol 2003, 69:6659-6668

53. Riviere D, Desvignes V, Pelletier E, Chaussonnerie S, Guermazi S, Weissenbach J, Li T, Camacho P, Sghir A: Towards the definition of a core of microorganisms involved in anaerobic digestion of sludge. ISME J 2009, 3:700-714

54. Treusch AH, Leininger S, Kletzin A, Schuster SC, Klenk H-P, Schleper C: Novel genes for nitrite reductase and Amo-related proteins indicate a role of uncultivated mesophilic crenarchaeota in nitrogen cycling. Environ Microbiol 2005, 7:1985-1995.

55. Nicol GW, Leininger S, Schleper C, Prosser Jl: The influence of soil pH on the diversity, abundance and transcriptional activity of ammonia oxidizing archaea and bacteria. Environ Microbiol 2008, 10:2966-2978.

56. Hatzenpichler R, Lebedeva EV, Spieck E, Stoecker K, Richter A, Daims H, Wagner M: A moderately thermophilic ammonia-oxidizing crenarchaeote from a hot spring. Proc Natl Acad Sci 2008, 105:2134-2139.

57. Mussmann M, Brito I, Pitcher A, Sinninghe Damsté JS, Hatzenpichler R, Richter A, Nielsen JL, Nielsen PH, Müller A, Daims H, et al: Thaumarchaeotes abundant in refinery nitrifying sludges express amoA but are not obligate autotrophic ammonia oxidizers. Proc Natl Acad Sci 2011, 108:16771-16776.

58. Hallin S, Lydmark P, Kokalj S, Hermansson M, Sorensson F, Jarvis A, Lindgren PE: Community survey of ammonia-oxidizing bacteria in full-scale activated sludge processes with different solids retention time. J Appl Microbiol 2005, 99:629-640.

59. Hammer O, Harper DAT, Ryan PD: PAST: Paleontological Statistics Software Package for Education and Data Analysis. Palaeontologia Electronica 2001, 4.

60. DeLong EF: Archaea in Coastal Marine Environments. PNAS 1992, 89:5685-5689

61. Hall TA: BioEdit: a user-friendly biological sequence alignment editor and analysis program for Windows 95/98/NT. Nudl Acids Symp Ser 1999, 41:95-98.

62. Huber T, Faulkner G, Hugenholtz P: Bellerophon: a program to detect chimeric sequences in multiple sequence alignments. Bioinformatics 2004, 20:2317-2319

63. Ashelford KE, Chuzhanova NA, Fry JC, Jones AJ, Weightman AJ: New Screening Software Shows that Most Recent Large 16S rRNA Gene Clone Libraries Contain Chimeras. Appl Environ Microbiol 2006, 72:5734-5741.

64. Felsenstein J: PHYLIP (Phylogeny Inference Package). 3.6 edition. Seattle: Department of Genome Sciences, University of Washington; 2005. Distributed by the author.

65. Marzorati M, Wittebolle L, Boon N, Daffonchio D, Verstraete W: How to get more out of molecular fingerprints: practical tools for microbial ecology. Environ Microbiol 2008, 10:1571-1581.

66. Mertens B, Boon N, Verstraete W: Stereospecific effect of hexachlorocyclohexane on activity and structure of soil methanotrophic communities. Environ Microbiol 2005, 7:660-669.

67. Smith CJ, Danilowicz BS, Clear AK, Costello FJ, Wilson B, Meijer WG: T-Align, a web-based tool for comparison of multiple terminal restriction fragment length polymorphism profiles. FEMS Microbiol Ecol 2005, 54:375-380.

68. Dunbar J, Ticknor LO, Kuske CR: Phylogenetic Specificity and Reproducibility and New Method for Analysis of Terminal Restriction Fragment Profiles of 16S rRNA Genes from Bacterial Communities. Appl Environ Microbiol 2001, 67:190-197.

69. Legendre P, Legendre L: Numerical Ecology. 2nd English edition. Amsterdam: Elsevier Science BV; 1998
70. Shyu C, Soule T, Bent S, Foster J, Forney L: MiCA: A Web-Based Tool for the Analysis of Microbial Communities Based on Terminal-Restriction Fragment Length Polymorphisms of $16 \mathrm{~S}$ and $18 \mathrm{~S}$ rRNA Genes. Microb Ecol 2007, 53:562-570.

71. Wang Q, Garrity GM, Tiedje JM, Cole JR: Naive Bayesian Classifier for Rapid Assignment of rRNA Sequences into the New Bacterial Taxonomy. Appl Environ Microbiol 2007, 73:5261-5267.

72. Daims H, Stoecker K, Wagner M: Fluorescence in situ hybridization for the detection of prokaryotes. In Advanced Methods in Molecular Microbial Ecology. Edited by Osborn AM, Smith CJ. UK: Bios-Garland, Abingdon; 2005:213-239.

73. Raskin L, Stromley JM, Rittmann BE, Stahl DA: Group-specific $16 \mathrm{~S}$ rRNA hybridization probes to describe natural communities of methanogens. Appl Environ Microbiol 1994, 60:1232-1240.

74. Crocetti G, Murto M, Bjornsson L: An update and optimisation of oligonucleotide probes targeting methanogenic Archaea for use in fluorescence in situ hybridisation (FISH). J Microbiol Methods 2006 65:194-201.

75. Amann Rl, Binder BJ, Olson RJ, Chisholm SW, Devereux R, Stahl DA: Combination of $16 \mathrm{~S}$ ribosomal-RNA-targeted oligonucleotide probes with flow-cytometry for analyzing mixed microbial-populations. Appl Environ Microbiol 1990, 56:1919-1925.

doi:10.1186/1471-2180-12-140

Cite this article as: Fredriksson et al: Diversity and dynamics of Archaea in an activated sludge wastewater treatment plant. BMC Microbiology 2012 12:140

\section{Submit your next manuscript to BioMed Central and take full advantage of:}

- Convenient online submission

- Thorough peer review

- No space constraints or color figure charges

- Immediate publication on acceptance

- Inclusion in PubMed, CAS, Scopus and Google Scholar

- Research which is freely available for redistribution 